\title{
Span-conditioned allomorphy and late linearization: Evidence from the Classical Greek perfect
}

\section{Glossa}

a journal of general linguistics

RESEARCH

\section{SYLVIA L. R. SCHREINER (D)}

\section{]u[ubiquity press}

\footnotetext{
Abstract

Data from the perfect in Classical Greek provide empirical evidence for inwardly- and outwardly-sensitive span-conditioned allomorphy and indicate the need for a postVocabulary Insertion linearization process. The data also support the extremely late computation of the phonology of reduplicants. Perfect aspect in Classical Greek is realized via three distinct exponents: a reduplicative prefix, a suffix -/k/ (for some verbs) or stem allomorphy (for others), and a dedicated set of agreement suffixes. I argue that this case of Multiple Exponence results from one direct exponent of the Aspect[perfect] head and two cases of allomorphy at other nodes conditioned by spans that include the Aspect[perfect] head. The reduplicant is a Vocabulary Item (RED) that instantiates Aspect. Its phonology is determined after both Vocabulary Insertion and linearization. The $-/ \mathrm{k} /$ suffix is an outwardly-sensitive allomorph of Voice[active] conditioned by the span (Aspect, Tense), and perfect stem allomorphy in verbs that show it is conditioned by (Voice, Aspect, Tense). The agreement suffixes are inwardlysensitive allomorphs conditioned by the span 〈Voice, Aspect, Tense, Mood〉. When taken together, the data indicate that Vocabulary Insertion must proceed cyclically, and that linearization must happen very late - after Vocabulary Insertion - since the realizations of both Voice[active] and AGR are conditioned by spans of hierarchically adjacent, rather than surface-contiguous, heads. The Greek data are essential for our understanding of the post-syntactic order of operations.
}

\section{CORRESPONDING AUTHOR:}

\section{Sylvia L. R. Schreiner}

George Mason University, US sschrei2@gmu.edu

\section{KEYWORDS:}

span-conditioned allomorphy; linearization; reduplication; Classical Greek; Distributed Morphology

TO CITE THIS ARTICLE: Schreiner, Sylvia L. R. 2021. Span-conditioned allomorphy and late linearization: Evidence from the Classical Greek perfect. Glossa: a journal of general linguistics 6(1): 64. 1-28. DOI: https:// doi.org/10.5334/gjgl.1400 


\section{Introduction}

In this paper I provide empirical support from Classical Greek for span-conditioned allomorphy, a late linearization process, and the (very) late phonological resolution of reduplicants. In most of the active voice paradigm of Classical Greek, perfect aspect has reflexes in three places simultaneously within a given inflected verb. These perfect forms display a reduplicative prefix, a suffix $(-\kappa,-/ \mathrm{k} / \mathrm{)}$ and/or a special form of the verb root, and a dedicated set of $\varphi$-feature inflections. For example:

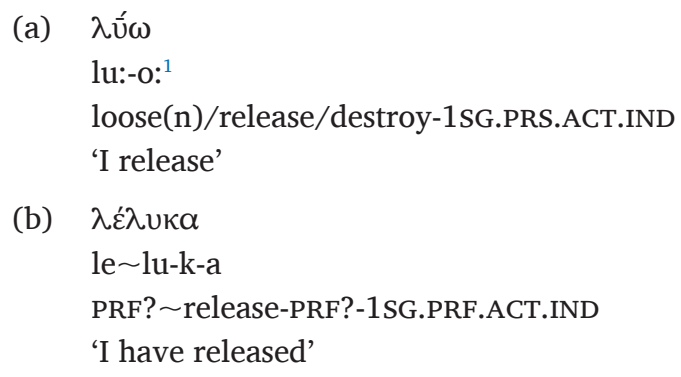

Each of these three morphemes brings its own challenges for determining its surface form. In part due to these complexities, each of these pieces also tells us something about the postsyntactic order of operations.

These data might at first seem to constitute what Caballero \& Harris (2012) term distributed exponence, in which "no single morphological marker can truly be said to realize a feature or category; the feature is, rather, realized by a combination of morphemes" (Caballero \& Harris 2012: 170). This is an extreme version of the phenomena encompassed by the terms extended exponence or multiple exponence (Matthews 1972; Carstairs-McCarthy 1987; Anderson 2001; Ackerman \& Stump 2004; Müller 2007; Baerman \& Corbett 2012; Caballero \& Harris 2012; Harris 2017), in which two or more exponents seem to be expressing the same morphosyntactic feature or property within the same word.

This type of redundancy presents challenges for many theories of morphosyntax, including the framework in which the present analysis is pursued, Distributed Morphology (Halle \& Marantz 1993). Multiple exponence could in theory result from a complex instantiation of a single syntacticosemantic head that is somehow realized in multiple places on the surface, something Distributed Morphology is not well-equipped to handle. Here, however, I conclude that what might seem to be multiple instantiations of an Aspect head in Classical Greek are in fact signals of three separate heads: Voice, Aspect, and AGR. The realizations of AGR and Voice in perfect forms are conditioned by a span including the Aspect[perfect] node, leading to a distinct three-part output unique to the perfect aspect. Thus I will gloss perfect forms as follows (repeating $1 \mathrm{~b}$ here as 2):

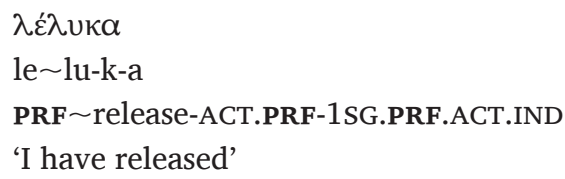

I gloss the suffixes $-/ \mathrm{k} /$ and $-\varnothing$ as ACT.PRF and the "equivalent" stem allomorphy as .ACT. PRF since (as I discuss in Section 3) they are conditioned by a span including active voice and perfect aspect; I use this as a shorthand for the entire conditioning span.

Below I argue that the reduplicative prefix alone in fact instantiates Aspect[perfect] (Section 2 ); that the $-/ \mathrm{k}$ / suffix is an allomorph of Voice[active] outwardly conditioned by the span 〈Aspect, Tense > and that stem allomorphy that occurs in place of or in addition to $-/ \mathrm{k} /$ in some roots is conditioned by the span 〈Voice, Aspect, Tense $\rangle$ (Section 3); and that the allomorphs of AGR are inwardly sensitive to the span of $\langle$ Voice, Aspect, Tense, Mood $\rangle$ (Section 4). In addition to providing empirical support for the existence of both inwardly- and outwardly- sensitive span-conditioned allomorphy, what makes the Greek perfect data particularly interesting is the surface order of the pertinent elements. This order makes it clear that hierarchical adjacency, rather than surface order, is conditioning the insertion of Vocabulary Items, and thus that

1 Data are drawn from Groton (2000) and Smyth (1920). I assume a null present tense suffix in all present tense forms (excluded from examples for ease of exposition). 
linearization must not occur until after Vocabulary Insertion is complete. The data also support Deal's (2016) contention that the phonology of a reduplicant is not determined until after both Vocabulary Insertion and linearization. In the next subsection I briefly present some background on Classical Attic Greek.

\subsection{The synthetic perfect in Classical Greek}

The data in this article are drawn from the Greek of the Classical period ( 800-300 BCE), in Attica. Under consideration is the "synthetic perfect"; that is, the inflected form(s) taken by a verb that expresses perfect meaning. These forms contrast with the periphrastic constructions used with some verbs in the present perfect, and with most verbs in the future perfect active and past middle-passive. ${ }^{2}$

Much previous work on the Classical Greek perfect focuses on its meanings (e.g., Wackernagel 1904; Chantraine 1927; McKay 1965; 1980; 1981; 1992; Rijksbaron 1984; Ringe 1984; Sicking \& Stork 1996; Gerö \& von Stechow 2003; Haug 2004) or on cataloguing forms (e.g., Smyth 1920 and countless pedagogical works; more recently, e.g., Groton 2000). Authors note resultative (Wackernagel 1904; Chantraine 1927; McKay 1980; 1981; Gerö \& von Stechow 2003) or "resultant state" (Haug 2004) uses; Gerö \& von Stechow (2003) also claim instances of experiential and universal perfects. Some verbs (generally statives) also show an "intensive" perfect (giving what Rijksbaron 1984: 38 calls the "highest degree of that state"), though this use is more common in pre-Classical Greek. I adopt Haug's (2004) position that the "abnormal" uses of the perfect (such as the intensive) are derivable semantically in the same way as the typical uses; furthermore, I will assume that there is, at least for a given time period, a unitary perfect semantics general enough to allow us to derive all the various readings. There is at least no variation in form that corresponds to the different shades of meaning. ${ }^{3}$

In the following sections I turn to each of the reflexes of perfect aspect in Classical Greek and the conclusions they lead us to about morphological structure and timing. In Section 2 I establish that the reduplicative prefix instantiates the Aspect node, examine the mechanics of the prefix, and modify an existing proposal by Zukoff (2017a; b) to formally account for the realizations that surface. In Section 3 I argue that the suffix $-/ \mathrm{k}$ / instantiates Voice in a case of outwardly sensitive span-conditioned allomorphy and reject several other possible analyses. In Section 4 I argue that the agreement marking that obtains in the perfect is the result of allomorphy in the AGR node in inwardly sensitive span-conditioned allomorphy. Section 5 is the conclusion.

\section{Reduplication: Linearization and phonological determination}

In this section I discuss the details of the reduplicative prefix in the Greek perfect and their implications for our understanding of morphosyntactic conditioning and linearization. I argue that this reduplication instantiates Aspect in the presence of the feature [perfect]. Its surface form(s) and position tell us two key things about the morphological order of operations: First, since it surfaces as a prefix but conditions the presence of other morphemes that end up as suffixes, the conditioning of those morphemes (Sections 3 and 4) cannot depend on the surface order of the exponents. Second, its surface form is dependent on the output phonology of the left side of the base, indicating that linearization must occur before the phonological computations take place, and that the reduplicant must have "access" to the base's output phonology.

I first show that this reduplication is the phonological exponent of Aspect whenever [perfect] is present. Second, I review the main existing proposals for reduplication within Distributed

2 As in (i):

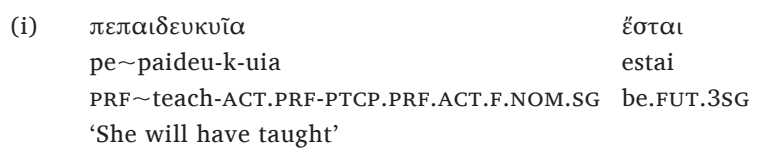

This periphrastic perfect (see e.g. Bentein 2012) employs an inflected participle and the tense-inflected auxiliary 'be'. I do not address this form here, but the perfect participle in this construction generally shows the same patterns as the inflected verb. I present data from the "thematic" verbs (whose first person present active indicative forms end in $-\omega(/ \mathrm{o}: /))$; at least parts of the analysis would also apply to the "athematic" verbs (analogous forms in $-\mu \mathrm{t} / \mathrm{mi} /$ ), as well. 
Morphology. Then, adopting a piece-based approach to reduplication after Haugen (2008; 2011), I provide an explanation of how this phonological exponent comes to surface where it does, with the forms it surfaces with. Finally, I introduce and extend Zukoff's (2017a; b) account of this interesting case of morphological fixed segmentism, and offer a proposal for how the phonology reads the Vocabulary Item in such a case, arguing against Zukoff's treatment of the two parts of the reduplicant as "two morphemes".

\subsection{Aspect is instantiated by reduplication}

As introduced above, perfect aspect is indicated in three distinct positions on the Classical Greek verb. I will argue that the $-/ \mathrm{k} /$ suffix and stem changes are instantiations of Voice[active] conditioned by a span including Aspect[perfect], and that the agreement suffixes instantiate AGR in a similar context. The reduplication on the left side of the verb, however, signals nothing in these forms other than perfect aspect. All perfect forms, regardless of tense, mood, voice, person, or number, show reduplication. In Table 1, the distinct ${ }^{4}$ perfect forms of $\pi \alpha$ เ $\delta \varepsilon v \omega$ /paideuo:/ 'I teach' are listed, with the reduplicant emphasized. ${ }^{5}$

\begin{tabular}{|c|c|}
\hline Present perfect active indicative & pepaideuka \\
\hline Past perfect active indicative & epepaideuke: \\
\hline Perfect active subjunctive & pepaideuko: \\
\hline Perfect active optative & pepaideukoimi \\
\hline Perfect active imperative & pepaideuke \\
\hline Perfect active infinitive & pepaideukenai \\
\hline Future perfect active infinitive & pepaideusein \\
\hline Present perfect middle/passive indicative & pepaideumai \\
\hline Past perfect middle/passive indicative & epepaideume:n \\
\hline Future middle/passive indicative & pepaideusomai \\
\hline Perfect middle/passive imperative & pepaideuso \\
\hline Perfect middle/passive infinitive & pepaideust ${ }^{\mathrm{h}}$ ai \\
\hline Future perfect middle/passive infinitive & pepaideusesthai \\
\hline Perfect active participle & pepaideuko:s \\
\hline Future perfect active participle & pepaideuso:n... \\
\hline Perfect middle/passive participle & pepaideumenos... \\
\hline Future perfect middle/passive participle & pepaideusomenos... \\
\hline
\end{tabular}

Given that reduplication is always present in forms with perfect meaning, and that it is an indicator only of perfect meaning in those forms, I take it to be the primary signal of the perfect: It instantiates the Aspect node when the [perfect] feature is present. The basic patterns of perfect reduplication, predictable from the phonology of the root, are summarized and exemplified in Table 2 (after Smyth 1920, Groton 2000). The reduplicant is emphasized in the right-hand column. Full examples can be found in the Appendix. Note that part of the reduplicant is always the fixed segment /e/ (and in fact this is sometimes the entirety of the reduplicant). ${ }^{6}$

\footnotetext{
4 The future perfect active indicative, perfect middle/passive subjunctive, and perfect middle/passive optative are formed periphrastically with perfect participles and forms of the verb eífí /eimi/ 'be'.

5 Note that not all instances of reduplication in Classical Greek signal perfect aspect. Some verbs, for example, also have reduplicated presents (see Zukoff $2017 \mathrm{~b}$ for an account of this phenomenon) or reduplicated aorists (see Grestenberger 2015a). These forms have different personal endings and often have different stems/changes to the root.

6 Note that the realization of the tense head when it is specified for past is also /e/- (see the past tense examples in Table 1). This is presumably accidental homophony, as the two can co-occur in the same form (the past perfect) and the /e/ in perfect reduplication appears across tenses, not just in the past.
}

Table 1 Perfect forms of /paideuo:/ 'I teach'. 


\begin{tabular}{|c|c|c|c|}
\hline If the root begins in... & ex. & Reduplicant is... & ex. \\
\hline A single aspirated stop & $t^{\text {h }} u o:$ & Corresponding plain stop $+/ \mathrm{e} /$ & te-thuka \\
\hline Stop + liquid or nasal & blepo: & That stop + /e/ & be-blepha \\
\hline “Double” C (e.g. $\zeta / z d /)^{7}$ & zde:teo: & le/ & e-zde:teka \\
\hline Any other C cluster & sphallo: & le/ & e-sphalka \\
\hline $\mid \mathrm{r} /$ or $/{ }^{\mathrm{h}} \mathrm{r} /$ & hripto: & /e/ (and /r/ doubles) & e-rripha \\
\hline Any other single $C$ & luo: & That $C+/ e /$ & le-luka \\
\hline A vowel & et ${ }^{\text {helo: }}$ & Lengthened form of that vowel ${ }^{8}$ & e:- $\mathrm{t}^{\text {hele:ka }}$ \\
\hline
\end{tabular}

Table 2 Patterns of perfect reduplication.

In the next section I consider existing approaches to reduplication in Distributed Morphology, before adopting one in the following section.

\subsection{Reduplication in Distributed Morphology}

The challenge of reduplication for piece-based theories like Distributed Morphology is that the reduplicant gains its phonological identity in reference to the phonology of the base, rather than being associated with its own phonological piece (see e.g. Haugen 2008; 2011; Cook 2013). In Distributed Morphology terms, this means that instead of a Vocabulary Item with a phonological string and a context for insertion, we have a situation in which there is a context (e.g., the feature [perfect] on Aspect), but no invariant or even simply phonologically conditioned string to insert. The reduplicant must instead reference the output of any phonological processes that apply to the root.

As Haugen $(2008 ; 2011)$ details, two types of proposals have been made regarding reduplication in Distributed Morphology: ${ }^{9}$ treating it as the result of a specialized Readjustment Rule, or as a special kind of affix. In what follows, I adopt the latter type of approach; first, though, I briefly summarize two major readjustment accounts and Haugen's (2008; 2011) arguments against such analyses.

\subsubsection{Reduplication as readjustment}

The Distributed Morphology approaches to reduplication that do not treat it as an affix employ a specialized Readjustment Rule. The two recent major readjustment-based analyses of reduplication in DM, ${ }^{10}$ Raimy (2000) and Frampton (2009), both take reduplication to "result from a [phonological] readjustment operation on some stem triggered by a (typically null) affix" (Haugen 2011: 1). Raimy's (2000) approach focuses on "precedence" in the representations of words: "A novel representation for reduplication arises from the clarification of precedence information in morpho-phonological representations, resulting in the possibility of loops..." (Raimy 2000: 1). These "loops" demarcate what of the representation gets repeated. The reduplication occurs when "reduplicative morphemes specify a vocabulary item that triggers a readjustment which creates a loop in the temporal structure of a previously spelled out vocabulary item" (Raimy 2000: 6-7). These (often phonologically null) reduplicative morphemes thus adjust the sequence of phonological "events" in a string, allowing for the repetition of segments.

7 The pronunciation of the letter zeta is somewhat contested. Many sources argue for /zd/ (e.g., Allen 1968), while others have argued for /dz/ (e.g., Teodorsson 1979). Regardless, it is treated as a "double" consonant for perfect reduplication - that is, as a cluster (and not a stop-sonorant one).

8 That is, the reduplicant is a copy of the initial vowel; the two resulting vowels follow language-wide rules of coalescence. Exceptionally, $\alpha$ /a/ "lengthens" to $\eta / \mathrm{e}: /$ instead of $\bar{\alpha} / \mathrm{a}: /$. A small (phonologically unpredictable) set of vowel-initial roots instead display what is known as "Attic" reduplication, copying initial VC as well as lengthening the first vowel in the root. For example, the root /eleuth-/ has the perfect /ele:louth-/ (where we would expect /e:lelouth-/ otherwise). Zukoff (2017a; b) addresses Attic reduplication at length, concluding that it arose as a case of phonotactic repair in a previous stage of the language, such that at the stage of Greek considered here, indexation of particular lexemes was involved and apparent in the constraints.

9 As reduplication is not the main focus of the current article, I focus on the work that has been undertaken within Distributed Morphology.

10 There are a number of proposals from outside Distributed Morphology that treat reduplication as the morphological (e.g. Anderson 1992; Stoneham 1994) or phonological (e.g. Aronoff 1976) "readjustment" of a stem. 
Frampton's Distributed Reduplication calls for a two-stage reduplication process: The morphology inserts a "transcription juncture" into a word's timing tier; these transcription junctures are then "interpreted as instructions which trigger and guide the duplication and/or truncation of certain material" (Frampton 2009: 2). Frampton criticizes Raimy's proposal: The adjustment Raimy undertakes to the timing tier, making it "nonlinear", "makes it impossible to build syllable and prosodic structure" (Frampton 2009: 7). This means that Raimy's account misses out on the important benefits brought by prosodic morphology. In addition, Haugen (2011) observes, Raimy's theory yields incorrect predictions about durative reduplication in Tawala.

While Frampton's account allows for the use of prosody in some places (feet can be targeted, as they are morphological as well as prosodic constituents (Frampton 2009: 78)), it faces other challenges. From a theoretical standpoint, Haugen (2010, 2011) calls out Distributed Reduplication for involving too many ad hoc pieces of machinery (and Haugen, in fact, shows that Frampton's 2009 account cannot make sense of the Tawala data, either). The requirement that reduplicants be a separate kind of morpheme from bases is a problem for both Raimy (2000) and Frampton (2009), as well as for Inkelas \& Zoll (2007). Haugen (2008; 2011) thus rejects the readjustment approach in favor of an affixal explanation.

\subsubsection{Reduplication as affixation}

Haugen's (2008; 2011) proposal for reduplication follows Marantz (1982) and Travis (1999; 2001), as well as most Optimality Theoretic work (notably McCarthy \& Prince 1993; 1995) in attributing reduplicative behavior to an affix rather than to a readjustment rule.

Marantz (1982) approaches reduplication in light of two major issues: one, the problem (noted by McCarthy 1979) of the inevitable overgeneration yielded by existing proposals for rules or notations for reduplication; and two, the "unusual interaction" (Marantz 1982: 435) between morphology and phonology common with reduplication (as discussed by Wilbur 1973). His proposal is to reduce reduplication to a "normal" instance of affixation - the only thing special is "the resemblance between the affix and the stem to which it is attached" (Marantz 1982: 436). Marantz claims that his approach removes the need for specialized ordering and conditions placed on morphological and phonological rules. The "simple procedure", drawing on McCarthy's (1979; 1981) approach to Arabic verbal paradigms, involves affixing a CV "skeleton" morpheme to a stem, copying "the entire phonemic melody of the stem" (Marantz 1982: 437), and then linking that melody to the skeleton.

Travis (1999) disagrees with Marantz's (1982) position that reduplication is only minimally different from normal affixation. In addition to the obvious difference that reduplication "copies" phonological material from elsewhere, she cites data from Tagalog, for instance, which shows reduplication that appears in more than one location in different word forms, and sometimes allows speakers alternatives of where the reduplication appears (Travis 1999: 318). She also claims that there is often a link between form and function in reduplication, in that many instances of it across languages have quantificational meanings. She proposes the Form/ Function Mapping Hypothesis: "The form of a (reduplicative) affix will mirror the function of a (reduplicative) affix" (Travis 1999: 323). That is, within a given language, within a particular extended projection, different reduplicative forms can yield different meanings. She actualizes this proposal with a RedP - a special phrasal level whose head is the location for insertion of the reduplicative affix.

Travis (2001) extends this approach. She opposes the trend since Marantz (1982) of treating the core of reduplication as being in the domain of phonology only, arguing instead that reduplication is invariably created by the syntax. She argues that what she calls "phonological reduplication" (the type we have been discussing here) results from head-to-head movement and feature checking of a head. She no longer assumes a special phrase dedicated to the reduplicative morpheme (RedP); instead, reduplication is the filling (by copying) of a position that is "independently available in the syntax" (Travis 2001: 11) - e.g. Number, in the nominal domain, or E(vent) in the verbal one. As Haugen (2008) notes, however, Travis' (1999) Form/Function Mapping Hypothesis is contradicted by data from a number of languages, including Yaqui.

Haugen's $(2008 ; 2009 ; 2011)$ approach to reduplication as affixation will form the basis of my analysis of Classical Greek perfect reduplication here. Like Marantz (1982) and Travis (1999; 2001), he treats reduplication as affixation, rather than readjustment. His approach departs 
significantly from the process-based accounts of Raimy (2000) and Frampton (2009). However, he also makes a number of additions and adjustments to Marantz's and Travis' proposals. For instance: While reduplicative "morphemes" (Vocabulary Items) are inserted into the syntax like other affixes, they do have properties that distinguish them from "regular" affixes (notably, their interaction with prosody); reduplicants instantiate a functional head like any other affix, rather than a specialized "RedP"; and we must distinguish between a morphosyntactic target ("the morphosyntactic domain to which reduplication applies" Haugen 2008: 79) and a phonological base ("that morphophonological constituent from which the reduplicant copies to fill in its own phonological material" Haugen 2008: 79) for reduplication.

Haugen's (2008; 2009; 2011) main claims of interest to us here are: (1) Reduplication is affixation; and (2) We must distinguish between morphosyntactic targets and phonological bases for reduplication. Haugen argues for these points primarily from Uto-Aztecan data. In my analysis below I adopt an affixation approach to reduplication and show that the Classical Greek data also support point (2).

\subsection{Greek perfect reduplication is an affix whose phonology is determined very late}

I follow Haugen's (2008; 2009; 2011) proposal for reduplication in Distributed Morphology here. Under this type of approach, the surface form of a reduplicant obtains from a special kind of Vocabulary Item, RED, whose phonological output is derived in the phonology via correspondence with a base. First, the morphosyntactic structure is built in the narrow syntax and Morphological Structure via the application of syntactic operations including Merge, Copy, etc.; and morphological operations such as Impoverishment, Fission, Fusion, etc. Vocabulary Insertion and linearization take place after these morphological adjustments. With these operations and adjustments completed, the surface phonology can be determined via Correspondence Theoretic means in the phonology proper. The Vocabulary Items inserted in the morphosyntax are the inputs to the Optimality Theoretic tableaux; in very simple cases, a Vocabulary Item directly provides the phonological information that will end up surfacing. In the case of reduplication, the phonological processes involved will adjust the phonological value of the Vocabulary Item accordingly. This allows morphology to interact with syntax through structure-building (via typical Distributed Morphology mechanisms), and to interact with phonology through what we might call output-building (typical Correspondence Theory mechanisms). ${ }^{11}$

In the Greek data, we see that RED surfaces as a prefix whose phonology is dependent on the phonology of the left side of the verb. It must therefore be the case that RED is in place linearly before the phonology undertakes its operations. In this way, the data support Deal's (2016) contention that the actual phonological instantiation of a reduplicant must be extremely late after Vocabulary Insertion and linearization.

As mentioned in Section 1.1, I assume a core invariant perfect semantics to be present in the Classical Greek perfects, from which the less canonical meanings can be derived semantically. Since the meaning conveyed is that of perfect aspect, I assume RED to instantiate the head of a grammatical/ outer AspectP. I take there to be a single morphosyntactic feature involved in the expression of perfect aspect, which I will call [perfect]. The Vocabulary Item for perfect is seen in (3):

Vocabulary Items competing for insertion into Aspect (partial) [perfect] $\leftrightarrow$ RED

This Vocabulary Item will compete for insertion into the Aspect terminal node. ${ }^{12}$ The perfect contrasts with the aorist in both finite and non-finite verb forms, ${ }^{13}$ often realized with the suffix

11 See Haugen (2011), Section 4 for an overview of this process.

12 This same Vocabulary Item will also apply in the case of periphrastic perfects; the difference between the finite form in synthetic perfects and the non-finite form in periphrastic ones will be a matter of the Vocabulary Items competing for insertion into other heads (Tense, Mood, Voice). Since the periphrastic perfects involve a form of the verb cífí /eimi/ 'be', the structure will necessarily include an additional VP.

13 In finite forms, aorist aspect is only ever realized in the past tense (marked with the "temporal augment" prefix $\varepsilon-/ e /-)$ - there is no present or future aorist form. However, there are aorist infinitives and participles, and they show the same $-\sigma-/ \mathrm{s} /$ suffix (etc. - not all verbs use this form). Thus I take $-\sigma-/ \mathrm{s} /$ to be the marker of aorist aspect, rather than the combination of $\varepsilon-/ \mathrm{e} /-$ plus $-\sigma-/ \mathrm{s} /$ marking an aorist "tense" in finite forms, as it is often described in traditional grammars. 
$-\sigma-/ s /$ (and different suffixes for agreement); and with the imperfective, which has no overt phonological realization. For example:

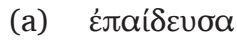
e-paideu-s-a
PST-teach-AOR-1SG.PST.AOR.ACT.IND
'I taught'

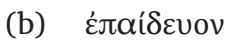
e-paideu- $\varnothing$-on
PST-teach-IPFV-1SG.PST.IPFV.ACT.IND
'I was teaching'

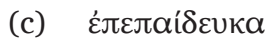
e-pe $\sim$ paideu-k-a
PST-PRF teach-ACT.PRF-1SG.PRF.ACT.IND
'I had taught'

We arrive at the following list of Vocabulary Items that compete for insertion into Aspect:

(5)

$$
\begin{aligned}
& \text { Vocabulary Items competing for insertion into Aspect } \\
& \text { [perfect] } \leftrightarrow \text { RED } \\
& \text { [aorist] } \leftrightarrow / \text { s/ } \\
& \text { elsewhere } \leftrightarrow \varnothing
\end{aligned}
$$

After the syntax, at Vocabulary Insertion, RED will win the competition and be inserted in an Aspect terminal node specified for [perfect]. This brings us to a point where the abstract morpheme RED is in the correct position hierarchically, as in (6) (abstracting away from the particular root and features of other heads):

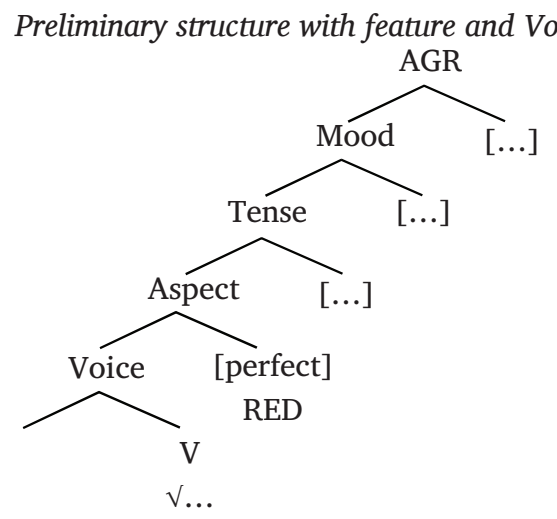

Noyer (1992/1997) takes Vocabulary Items to be lexically specified with a special feature marking them as prefixes or suffixes, but his account is not concerned with the details of whether or how this feature is interpreted by linearization. Let us specify the RED Vocabulary Item as a prefix:

$$
\text { [perfect] } \leftrightarrow \text { RED- }
$$

The order of Vocabulary Insertion and the eventual linear order of affixes is not related, as Halle (1997: 135) acknowledges. Vocabulary Insertion itself presumably proceeds "inside-out" (Bobaljik 2000; Embick 2010), that is, hierarchically up the tree.

If linearization happens at Vocabulary Insertion (Embick \& Noyer's 2001 Late Linearization Hypothesis) or after, and can "read" the information about whether each Vocabulary Item is specified as a prefix or suffix, then the Vocabulary Items can end up in the correct place without any special dislocation mechanism having to be posited. (Sections 3 and 4 provide further insight into the process of Vocabulary Insertion.) The partial linearized form can be seen in (8) (I employ Embick \& Noyer's 2001 notation $a * b$ "to denote a requirement that $a$ must linearly precede $b$ and be adjacent to $b$ " p. 562):

$$
[\text { RED- * }[V] * \ldots]
$$


With the reduplicant linearized as a prefix to the root, it is in a position for its surface form to be correctly determined by the phonology.

\subsection{The phonology of RED}

The realizations of the reduplicant that surface in Greek perfect aspect depend on the form of the first one or two segments of the surface form of the verb, and always include the fixed segment /e/. Both of these facts present challenges. For reference, I repeat Table 2 here as Table 3.

\begin{tabular}{|c|c|c|c|}
\hline If the root begins in... & ex. & Reduplicant is... & ex. \\
\hline A single aspirated stop & $t^{\text {thuo: }}$ & Corresponding plain stop $+/ \mathrm{e} /$ & te-thuka \\
\hline Stop + liquid or nasal & blepo: & That stop $+/ \mathrm{e} /$ & be-blep ${ }^{\mathrm{h}} \mathrm{a}$ \\
\hline “Double" C (e.g. $\zeta / z d /)$ & zde:teo: & le/ & e-zde:teka \\
\hline Any other C cluster & sphallo: & le/ & e-sphalka \\
\hline$/ \mathrm{r} /$ or $/{ }^{\mathrm{h}} \mathrm{r} /$ & hripto: & /e/ (and /r/ doubles) & e-rripha \\
\hline Any other single $C$ & luo: & That $C+/ e /$ & le-luka \\
\hline A vowel & et ${ }^{\text {helo: }}$ & Lengthened form of that vowel & e:- $\mathrm{t}^{\text {hele:ka }}$ \\
\hline
\end{tabular}

Roots with initial stop-sonorant clusters copy the stop and add /e/; other C-initial roots add /e/; and regular V-initial roots lengthen the V. ${ }^{14}$ In this section I first consider what the Greek data tell us about the question of the target/base for reduplication, and then pursue an adjustment to Zukoff's (2017a) account.

\subsubsection{Bases and targets for reduplication}

The overarching issue here is the "base" and its relationship with the reduplicant. First, it is necessary to distinguish the morphosyntactic target from the phonological base, as Haugen (2008; 2009; 2011) does. The morphosyntactic target of perfect reduplication I assume with Haugen (2008) and Travis (2001) (among others) to be the morphosyntactic sister of the reduplicant. But consider the verb in (9):

(9)

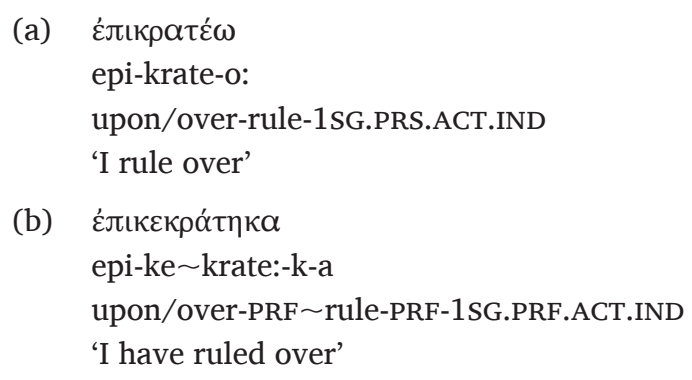

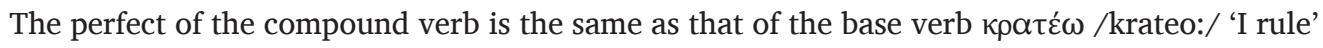
(10) but with /epi/- prefixed to the reduplicated form.

(10)

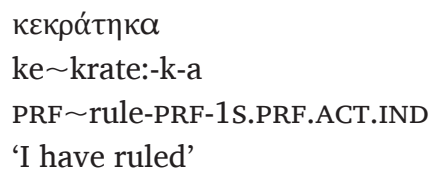

If the morphosyntactic target of reduplication were the root with the prefix already attached,

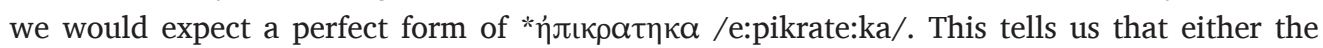
prefix is merged at the very end of the derivation (which would render mysterious the semantic scope of perfect over the meaning of the compound verb), or there is some kind of dislocation of the prefix in the morphology - after Aspect is fixed hierarchically outside the root but before the phonological computation of RED-.
Table 3 Patterns of perfect reduplication. 
Evidence that the target is what we might call the "root" form and not, say, the present stem, comes from the behavior of verbs whose present active indicative form have an infixed nasal. For instance, the verb $\mu \alpha v \theta \alpha \dot{v} \omega \mathrm{m} / \mathrm{mant}^{\mathrm{h}}$ ano:/ 'I learn' is built on the root $\mu \alpha \theta-/ \mathrm{mat}^{\mathrm{h}} /$ (Liddell \&

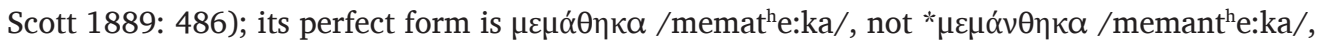
as would be expected if the present stem was the target.

Then, the (phonological) base for reduplication must be determined. This topic is the subject of Haugen's (2009) work. He notes that McCarthy \& Prince's (1986) prosody-driven account improved upon Marantz's (1982) theory in recognizing that reduplicative bases needed to be able to be limited to only part of the stem (for cases like Yidiny , where the base must be limited to the first foot of the stem) and also cites Yaqui as showing "syllable copy" reduplication, which is more easily dealt with in such a theory (Haugen 2009: 506). However, he notes, most theories of reduplication (including McCarthy \& Prince 1993) at least implicitly assume that the entire stem is the base for reduplication, and that no other demarcation of a more limited base is allowed.

But this type of approach, Haugen (2009) argues, does not easily account for cases like the double reduplication in Mainland Comox discussed by Urbanczyk (2000). Haugen concludes that what is needed to account for the empirical data in a "theoretically appealing way" (Haugen 2009: 512) is something like Shaw's (2005) Constituent Base Hypothesis, which allows both morphological and prosodic constituents to be bases for reduplication. He leaves for future work the task of finding "other cases of delimited bases," to test the predictions of the Hypothesis. Classical Greek is just such a case, as is made clear in Zukoff's (2017a; b) Correspondence Theoretic analysis, discussed in Section 2.4.2.

In the type of account pursued here, once the reduplicant is in place in the syntax, it is "passed off" to the phonology proper. I agree with Haugen (2011) that to account for prosodic morphology like reduplication, we need more than just "Black Box Phonology" - in which the morphological component deals only extremely locally, and does not take heed of generalizations about phonological surface forms. ${ }^{15}$ Haugen argues, and I concur, that we need to be able to reference precisely these phonological outputs in order to make sense of reduplication data. Specifically, as Haugen (2011: 10) notes, at least some cases of reduplication require what Inkelas \& Zoll (2007) refer to as "base-dependence":

Base-dependence arises when the determination of the phonological form of one copy in a reduplication construction (i.e. the "reduplicant") is dependent upon some aspect, morphological or phonological (prosodic), of the output form of the other copy in the construction (i.e. the reduplicant's "base") (cf. Inkelas and Zoll 2007:

92-7). (Haugen 2011: 10)

This kind of dependence is ruled out, for instance, by Inkelas \& Zoll's (2007) Morphological Doubling Theory. Haugen \& Hicks Kennard (2011), however, argue that base dependence is required to account for data in a number of languages. It is clear that the Classical Greek data also require a morphological theory that allows "access" to the phonology, and not just an explanation (like Inkelas \& Zoll's) based on semantic identity. Haugen (2008; 2009; 2011) accomplishes this via blending of Distributed Morphology with Correspondence Theory (McCarthy \& Prince 1995), which employs ranked faithfulness and markedness constraints, as in standard Optimality Theory. The key for the current analysis is that RED is a Vocabulary Item that instantiates Aspect; the Correspondence Theoretic mechanics of how the phonological output of RED is calculated are addressed thoroughly by Zukoff (2017a; b). I summarize his approach in 2.4.2, but the interested reader can refer to his work for further details.

\subsubsection{Accounting for the phonological output: Zukoff (2017a; b) and beyond}

The idea we have so far is that the instantiation of an Aspect head bearing the feature [perfect] in Greek is RED; this reduplicative "morpheme" will be the input to the phonology. Zukoff (2017a; b) provides a detailed Correspondence Theoretic account (within McCarthy \& Prince's 1995 Base-Reduplicant Correspondence Theory) of the set of interacting constraints at play in

15 Specifically, Haugen is critiquing the version of Distributed Morphology that Embick (2010) proposes, which locates such generalizations outside the grammar proper. 
this phonological calculation. His account improves on previous analyses of Greek reduplication (e.g. Steriade 1982; 1988; Fleischhacker 2005; Halle 2008) in that it is able to explain all the patterns seen in perfect reduplication, ${ }^{16}$ and also helps explain facts from the verbs that show reduplication in the present.

His basic account we can adopt fairly straightforwardly; however, the successful interaction of his constraints demands that the phonology actually be accessing two morphemes, RED and the fixed segment /e/. He notes (following Alderete et al. 1999) that there are two options for dealing with situations in which a fixed segment figures into reduplication: Either the segment is a copy of a vowel from the base that has been reduced (a "phonological analysis"), or the segment is a separate morpheme (a "morphological analysis"). Zukoff shows that a phonological analysis leads to a ranking paradox for the constraints he proposes. ${ }^{17}$

Here I first summarize Zukoff's approach to the reduplication, then make a proposal about the interaction between the output of the morphosyntactic component(s) and the phonological component to account for the phonology's need to treat RED and /e/ as two pieces.

First, the key constraints involved in Zukoff's (2017b) analysis are as follows:

- ONSET (Prince \& Smolensky 1993/2004): helps motivate the realization of the reduplicative copy (incurs a violation if /e/ surfaces without a preceding C)

- REDUP(RED) (based on Zuraw 2002): helps motivate the realization of the reduplicative copy (incurs a violation if RED is in the input but the output does not include Base and Reduplicant substrings)

- MAX-BR (McCarthy \& Prince 1995): motivates copying all segments of the base into the reduplicant

- ANCHOR-L-BR (McCarthy \& Prince 1995): ensures the C that appears in the output matches the root-initial consonant

- Align-/e/-L: A “size restrictor" constraint; outranking MAX-BR helps maintain a minimal reduplicant (incurs a violation for "for every segment that intervenes between the left edge of the exponent of the fixed segment affix /e/ and left edge of the prosodic word" (Zukoff 2017b: 41)). Ensures that the reduplicant does not end up as a full copy of the base

- *CLUSTER (*CC): advocates against the copying of the whole consonant cluster when outranking Align-/e/-L. This ensures that we end up with just the stop of stop-sonorant clusters copied in the output

- No Poorly-Cued RePetitions (*PCR) $\left(\approx{ }^{*} \mathrm{C}_{\alpha} \mathrm{VC}_{\alpha} / \mathrm{C}_{[- \text {-son }]}\right)$ : an "antirepetition" constraint; incurs a violation if matching consonants in the structure CVC precede an obstruent. This is to keep consonant copying from occurring in clusters that are not stopsonorant clusters

These constraints operate together on RED to ensure that the morpheme is realized overtly; that it copies segments of the base but not the entire base; that the segments that get realized are from the left side of the root; and that clusters are treated differently depending on their make-up.

This brings us to the potential ranking paradox. Given input like kton-, which yields _--e-ktonrather than $k$-e-kton- (since /kt/ is not a stop-sonorant cluster), the antirepetition constraint *PCR must outrank ONSET and REDUP(RED). Since we do not see kt-e-kton-, *PCR must outrank *CC. But why not just copy the second C, yielding t-e-kton-? This output does not incur ONSET or REDUP(RED) violations, while _--e-kton- does. The fact that _--e-kton- wins over $t-e-k t o n-$ indicates that the violation of ANCHOR-L-BR incurred by $t$-e-kton- is fatal. It must be the case that no such violation is incurred with the candidate _--e-kton-. On a phonological analysis of the fixed segment /e/ (i.e., if RED and /e/ are part of the same unit), _-e-kton- would violate

16 Including the otherwise mysterious Attic reduplication (see fn 8).

17 In addition, /e/ shows no signs (that I am aware of) of being a default vowel elsewhere in the language, and does not correspond to the characteristics for cross-linguistic defaults that Alderete, et al. discuss (arising from the place-markedness hierarchy of Prince \& Smolensky 1993; Lombardi 1997). 
ANCHOR ("since its leftmost reduplicant segment ([e]) would be in correspondence with a segment not at the left edge of the base (i.e., the root vowel)" (Zukoff 2017a: 468). Since this form does not incur an ANCHOR violation (again, it must not, since it wins out over the otherwise less marked t-e-kton-), it must be the case that the phonology is treating the /e/ in question as a separate piece, able to be operated on by separate constraints.

Thus, Zukoff argues that RED and /e/ must enter the phonological computations as "separate morphemes". By this he presumably means that they must in some way be separate units, available for individual application of constraints, etc., when they undergo phonological operations. However, Zukoff gives no hint as to what being "separate morphemes" might mean for RED and /e/. I find his decision to treat them as separate morphemes flawed in several ways.

First, there is no morphosyntactic or semantic evidence that RED and /e/ are separate entities in the syntax, the morphology, or the interpretive component. Zukoff himself notes, "as with schmreduplication and similar cases, it is unclear if these two morphs have distinct functions" (Zukoff 2017b: $40 \mathrm{fn} 11$ ). I showed above that reduplication appears across perfect forms. There is also evidence for $/ \mathrm{e} /$ in all the forms of reduplication. Although it may change on the surface due to rules of coalescence in the perfects that involve vowel-lengthening (see e.g. Zukoff 2017a, Section 2.2; 2017b, Section 2.2.2), its presence is detectable in copying environments $\left(\mathrm{CeC}\left(\mathrm{C}_{\text {son }}\right)\right.$ $\mathrm{V} . .$.$) , non-copying environments \left(\mathrm{eCC}_{\text {-son }} \mathrm{V}\right)$, vowel-initial environments (lengthening of $\mathrm{V}$ ), and Attic Reduplication environments (lengthening of root-internal initial V). Zukoff treats all these forms as containing /e/. The fate of the two "pieces" (the output of the computations on RED and the output of the computations on /e/) is entirely in the hands of the phonology - they are not distinct in the morphology or the syntax.

Consider that $\mathrm{C}+/ \mathrm{e} /$ is a case of morphological fixed segmentism. Alderete, et al. (1999) characterize this phenomenon as a case of an "overwriting" affix. Considering schmreduplication in English and $s$ - reduplication in Kamrupi, they state that "unlike conventional prefixes, šm- and $s$ - overlap with or "overwrite" the reduplicant, so their presence interferes with reduplicative copying" (p. 355). This is not what is happening in Greek. The segment /e/ does not interfere with copying the $\mathrm{C}$ part of the reduplicant, when that occurs. What seems to be happening is that the phonology is targeting RED as separate from /e/, despite their being a single entity in the eyes of the morphology. In short, the phonology needs to be able to treat them as separate pieces, even though they are part of the same unit in terms of morphosyntactic structure and meaning.

This can be accomplished if the phonological instantiation of an Aspect node specified for [perfect] has the shape RED/e/-. ${ }^{18}$

In the data at hand, the realization of the reduplicant appears as a copy of particular segments, plus /e/. This additional segment does not overwrite part of the base, as happens in schmreduplication; it simply exists alongside the (imperfect) copy of the base.

The phonology in a Vocabulary Item is essentially a set of instructions for the phonological component to follow. In a case where the instantiation is (for example) /da/, the phonology's instructions are roughly "undertake language-relevant operations (including the application of relevant constraints) on the segments $/ \mathrm{d} /$ and /a/, together in that order." The Vocabulary Item $\mathrm{RED} / \mathrm{e} /-$ would be similarly read by the phonology as "undertake language-relevant operations on RED and /e/, together in that order." Of course, RED is not a unique segment; but, its language-relevant operations could include a second layer of instructions, such as "make a copy of the base and undertake language-relevant operations on the segments of that copy." Treating this Vocabulary Item as made of two phonological elements allows the phonology to treat one morphosyntactic unit as two pieces phonologically.

In this section I have argued that Aspect, in the presence of the feature [perfect], is instantiated by RED/e/-. This is a special Vocabulary Item whose context for insertion is typical, but whose 
phonological instantiation is atypical - it is not determined until after Vocabulary Insertion and linearization, and includes a fixed segment. The fact that RED/e/- is dependent on the phonology of the left side of the root points to the necessity of very late (post-linearization) phonological resolution of the reduplicant, and to the need for it to be able to "access" the phonology of the base. In addition, these data point to an approach to morphological fixed segmentism in reduplication that treats the invariant segment as phonologically separate from the copying part of the Vocabulary Item. In the next section I address the second reflex of [perfect], the consonantal suffix.

\section{The suffix $-/ k /$ and stem allomorphy}

In this section I discuss additional reflexes of perfect aspect in active voice verbs, which have implications for our understanding of span-conditioned allomorphy and linearization. I argue that the suffix $-/ \mathrm{k}$ / instantiates Voice[active] in the context of a span in which two other heads (Aspect and Tense) are implicated. Perfects with this suffixation are traditionally called "first perfects". The stem allomorphy that alternates with $-/ \mathrm{k} /$ depending on the phonology of the root is outwardly dependent on a span of three heads (Voice, Aspect, and Tense). Perfects that show this stem allomorphy are traditionally called "second perfects". Furthermore, the choice between the Voice allomorphs $-/ \mathrm{k} /$ and $-\varnothing$ depends on the phonological content of the (right side of the) root, indicating that the root Vocabulary Item must already be spelled out when the Voice[active] Vocabulary Item is chosen. However, the choice of the correct allomorph also depends on the ability of Vocabulary Insertion to access hierarchical, rather than linear, information, about hierarchically higher elements. These facts together indicate that Vocabulary Insertion must proceed cyclically, and that linearization must occur after Vocabulary Insertion is complete. I consider each of these points in turn. In Section 3.1 I consider the $-/ \mathrm{k} / \mathrm{suffixing}$ ("first") perfects; in 3.2 I examine the stem allomorphy in "second perfects"; in 3.3 I present (and subsequently reject) alternative analyses; and in 3.4 I discuss the implications of these Vocabulary Items for linearization.

\subsection{Suffixed -/ k/ instantiates the [active] Voice head in "first perfects"}

In the previous section I argued that the prefix RED/e/- instantiates an Aspect node carrying the [perfect] feature. As mentioned, many perfect forms also show a reflex of perfect aspect on the right side of the root. In the active voice, in all tenses, aspects, and moods other than future infinitives and future participles, perfects display a suffix $-/ \mathrm{k} /$ or stem allomorphy, depending on the phonology of the root. Verb roots ending in vowels, dentals, liquids, and nasals (traditionally "first perfects") suffix -/k/; those ending in labials and velars (traditionally "second perfects") instead have a special stem form. ${ }^{19}$ A prototypical example of a verb with a "first" perfect is $\lambda \vec{v} \omega$ /luo:/, 'I loose/release/destroy', as seen in (11). The first person present active indicative is in (11a), the corresponding present perfect is in (11b), and the corresponding past perfect is in (11c).

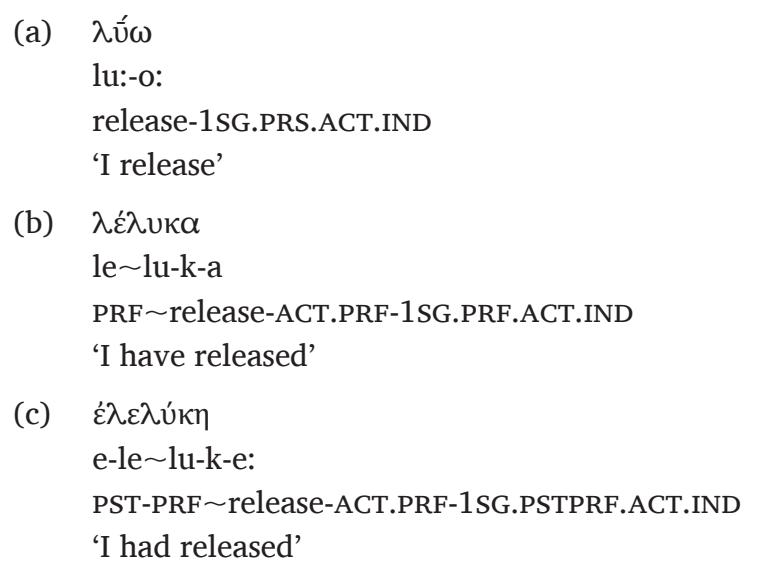

A typical example of verb with a "second perfect" is $\beta \lambda \dot{\varepsilon} \pi \omega$ /blepo:/ 'I see', as seen in (12).

19 A few verbs have both a "first" and "second" perfect form. For example, $\pi \varepsilon i$ i $\omega$ /peit ${ }^{\mathrm{h}} \mathrm{o}$ :/ 'I persuade' has

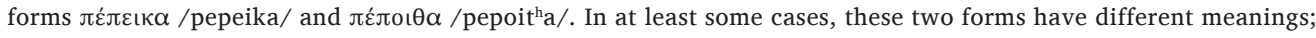
I assume these are synchronically different roots. 
(12)
(a) $\beta \lambda \dot{\varepsilon} \pi \omega$
blep-o:
see-1SG.PRS.ACT.IND
'I see'
(b) $\beta \varepsilon \dot{\beta} \beta \varepsilon \varphi \alpha \alpha$
be $\sim$ blep $^{\mathrm{h}}$-a
PRF $\sim$ See.ACT.PRF-1SG.PRF.ACT.IND
'I have seen'
(c) $\dot{\varepsilon} \beta \varepsilon \beta \lambda \dot{\varepsilon} \varphi \eta$
e-be $\sim$ blep ${ }^{\mathrm{h}}$-e:
PST-PRF $\sim$ See.ACT.PRF-1SG.PSTPRF.ACT.IND
'I had seen'

Table 4 (after Groton 2000; Smyth 1920) shows the patterns in question, and full examples can be found in the Appendix.

\begin{tabular}{|c|c|c|c|c|}
\hline & If the root ends in... & ex. & Change is... & ex. \\
\hline \multirow{3}{*}{$\begin{array}{l}\text { "First } \\
\text { perfects" }\end{array}$} & A vowel & agoreu-o: & Suffix /k/ & e:goreu-k-a \\
\hline & A dental (or $\zeta / z d /$ ) & peit ${ }^{\mathrm{h}} \mathrm{O}$ & Drop dental, suffix / k/ & pepei-k-a \\
\hline & A liquid or nasal & angello: & Suffix /k/ & e:ngel-k-a \\
\hline \multirow[t]{2}{*}{$\begin{array}{l}\text { "Second } \\
\text { perfects" }\end{array}$} & A labial ${ }^{20}$ & $\begin{array}{l}\text { blepo: } \\
\text { tribo: }\end{array}$ & Labial becomes $\varphi / \mathrm{p}^{\mathrm{h}} /$ & $\begin{array}{l}\text { beble } \mathbf{p}^{\mathrm{h}}-\mathrm{a} \\
\text { tetrip }\end{array}$ \\
\hline & A velar ${ }^{21}$ & $\begin{array}{l}\text { ago: } \\
\text { dio:ko: }\end{array}$ & Velar becomes $\mathrm{x} / \mathrm{k}^{\mathrm{h}} /$ & $\begin{array}{l}\text { e:k } \mathbf{k}^{\mathbf{h}}-\mathrm{a} \\
\text { dedio:} \mathbf{k}^{\mathrm{h}}-\mathbf{a}\end{array}$ \\
\hline
\end{tabular}

It is predictable whether a root will suffix $-/ \mathrm{k} /$ or not, based on the final segment in the root. Many roots that do not suffix -/k/ undergo predictable root changes (as seen in Table 4), but many other roots undergo unpredictable changes. These facts will help determine the content of the Vocabulary Items for $-/ \mathrm{k} /$ and the labial and velar roots.

We saw in the previous section that RED/e/- is present across perfect forms; I took it to be the instantiation of Aspect[perfect]. Perfect aspect is a necessary but not sufficient condition for the appearance of the $-/ \mathrm{k} /$ suffix/stem changes, however. Most notably, these right-side changes only occur in the active voice, as seen in (13) (using the same verbs from above as examples):

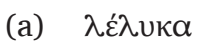
le $\sim$ lu-k-a
PRF $\sim$ release-ACT.PRF-1SG.PRS.ACT.IND
'I have released'
(b) $\lambda \varepsilon \dot{\lambda} \lambda u \mu a \mathrm{t}$
le lu-mai
PRF $\sim$ release-1SG.PRS.MP.IND
'I have been released'
(c) $\beta \varepsilon \dot{\beta} \lambda \varepsilon \varphi \varphi \alpha$
be $\sim$ blep ${ }^{\mathrm{h}}$-a
PRF $\sim$ See.ACT.PRF-1SG.PRF.ACT.IND
'I have seen'
(d) $\beta \dot{\beta} \beta \lambda \varepsilon \mu \mu \alpha$
be $\sim$ blem $^{22}$-mai
PRF $\sim$ see.MP.PRF-1SG.PRS.MP.IND
'I have been seen'

Table 4 Patterns of perfect "suffixation" for regular verbs.

$20 \pi \tau / \mathrm{pt} /$ drops dental / $\mathrm{t} /$ and then the root acts like a labial-final root.

21 Or orthographic $\tau \tau$ /tt/, which "hides" a stem-final $\kappa \iota / \mathrm{ki} /, \gamma \mathrm{l} / \mathrm{gi} /$, or $\chi \mathrm{\iota} / \mathrm{k}^{\mathrm{h}} \mathrm{i} /$.

22 Note that this root in fact displays a different kind of change in the middle-passive voice. 
They do not appear in non-perfect aspects:
lu:- $\varnothing$-o:
release-IPFV-1SG.IPFV.ACT.IND
'I release/am releasing'
(a) $\lambda \bar{u} \omega$
(b) है $\lambda \bar{u} \sigma \alpha$
e-lu:-s-a
PST-release-AOR-1SG.AOR.ACT.IND
'I released'
(c) $\beta \lambda \dot{\varepsilon} \pi \omega$
blep-o:
see-1SG.PRS.ACT.IND
'I see'
(d) $\varepsilon \beta \lambda \varepsilon \psi \alpha$
e-blep-s-a
PST-see-AOR-1SG.AOR.ACT.IND
'I saw'

And they appear across tenses and moods with the exception of future infinitives (15a) and future participles (15b):
(a) $\lambda \varepsilon \lambda \bar{u} \sigma \varepsilon เ v$
le $\sim$ lu:-s-ein
PRF $\sim$ release-FUT-INF.FUT.PRF.ACT
'to be going to have released'
(b) $\lambda \varepsilon \lambda \hat{u} \sigma \omega v$
le $\sim$ lu:-s-o:n
PRF release-FUT-PTCP.FUT.PRF.ACT.M.NOM.SG
'being going to have released'

Thus, the appearance of $-/ \mathrm{k}$ / or stem allomorphy is dependent upon not a single feature in a single head, as RED/e/- was, but on a combination of the featural content of Voice, Aspect, and Tense. Given that $-/ \mathrm{k}$ / appears only in the active voice and appears in a position after the verb root and before mood and agreement endings, we might imagine it is instantiating Voice, Aspect, or Tense.

We can rule out tense distributionally. We saw (as in 11c) that $-/ \mathrm{k} / \mathrm{co-occurs}$ with the past tense prefix /e/-. Then, in the indicative, most verbs form their future perfects periphrastically; however, there are two verbs that form their future perfect indicatives synthetically, and these show $-/ \mathrm{k} /+$ future $-/ \mathrm{s} /$, as expected if $/ \mathrm{k} /$ instantiates a head inside Tense. ${ }^{23}$ This can be seen

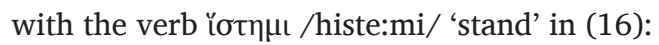

(16)

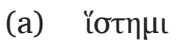
histe:-mi
stand-1SG.PRS.ACT.IND
'I stand'
(b) ह̌ бтฑка
heste:-k-a
PRF stand.ACT.PRF-ACT.PRF-1SG.PRF.ACT.IND
'I have stood'
(c) $\dot{\varepsilon} \sigma \tau \eta ́ \xi \omega$
he $\sim$ ste:-k-s-o:
PRF $\sim$ stand.ACT.PRF-ACT.PRF-FUT-1SG.FUT.ACT.IND
'I will have stood'

23 Grestenberger (2015b) argues that future -/s/ instantiates a high modal head, Mod, above T. This would not affect the analysis presented here, as a null exponent in T would allow it to get pruned (Embick 2010; see Section 4.1) and the resulting span would still condition the appearance of $-/ \mathrm{k} /$. 
We have already established that RED/e/- instantiates Aspect when [perfect] is present. If -/k/ and stem allomorphy were direct results of Aspect[perfect] as well, a second exponent would need to be involved that somehow managed to get expressed simultaneously with, and on the other side of the root from, RED/e/-. A simpler explanation is that these changes are the result of an allomorph of Voice[active] that is conditioned by the presence of [perfect] on Aspect, among other things. This is the analysis I pursue here; I briefly explore and ultimately reject the other possibility in Section 3.3. The structure (without Vocabulary Items) we have so far is as follows:

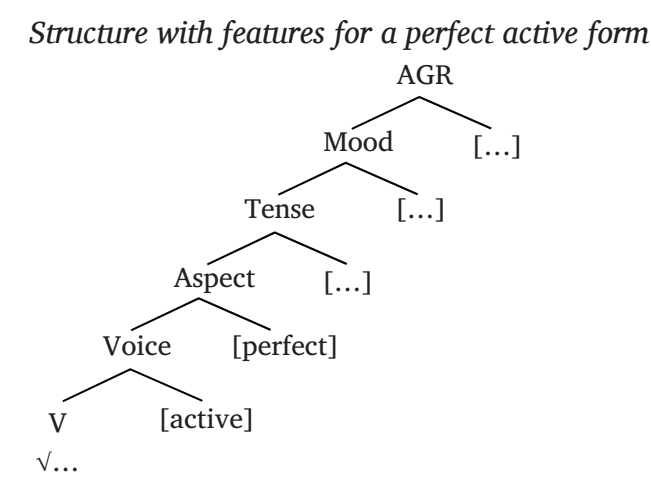

Now we must determine the Vocabulary Items in competition for insertion into the Voice[active] head. First, -/k/ must be in competition with a Vocabulary Item with a null phonological exponent, as active voice is unmarked in situations other than the ones under consideration:

$$
\begin{aligned}
& \text { Vocabulary Items competing for insertion into Voice (partial) } \\
& \text { [active] } \leftrightarrow \varnothing
\end{aligned}
$$

Then, above we saw that $-/ \mathrm{k} /$ occurs only in perfect aspect, does not appear in future infinitives or future participles, and does not appear after labials or velars; that is, the appearance of $-/ \mathrm{k} / \mathrm{in}$ Voice is dependent upon both its outward-looking morphosyntactic environment and its inwardlooking phonological environment. Importantly, the appearance of $-/ \mathrm{k} /$ is conditioned by the content not of a single head, but of two heads taken together: Aspect and Tense. These data thus provide empirical evidence for the existence of outwardly-sensitive span-conditioned allomorphy, supporting Merchant's (2015) Span Adjacency Hypothesis: Allomorphy is conditioned by structurally adjacent spans ${ }^{24}$ of terminal nodes, all of whose members are implicated in the conditioning. The span in question is 〈Aspect, Tense , as only certain combinations of features across these two heads permit $-/ \mathrm{k} /$ to appear. Thus the Vocabulary Item for $-/ \mathrm{k} /$ must include the following:

$$
\begin{aligned}
& \text { Voice[active] } \\
& \leftrightarrow /-\mathrm{k} / / \text {-labial, -velar] } \_ \text {Aspect[perfect] }{ }^{25} \text { Tense[-finite, -future] } \\
& \leftrightarrow /-\mathrm{k} / / \text { [-labial, -velar] } \_ \text {Aspect[perfect] Tense[ + finite] } \\
& \leftrightarrow-\varnothing \text { elsewhere }
\end{aligned}
$$

For a past perfect with $-/ \mathrm{k} /$, then, our structure with Vocabulary Items would be as follows:

$$
\text { Structure with features and Vocabulary Items for a past perfect with -/k/ }
$$

24 After Svenonius's (2012) definition, who was building upon Williams (2003), Abels \& Muriungi (2008), and Taraldsen (2010).

25 I leave open the possibility that the participles themselves will require further specification in Aspect and/or Tense (see e.g. Embick 2000; Cowper 2005); the Vocabulary Items at hand only need to ensure that the nonfinite future forms are ruled out. 
This allows us to account for the "first perfects", which suffix $-/ \mathrm{k} /$, and we can now turn to the stem-adjusting "second perfects". We will return to the implications of these Vocabulary Items for linearization in Section 3.4.

\subsection{Conditioning the stem allomorphy in "second perfects"}

Recall that in the cases that meet the morphological criteria for inserting $-/ \mathrm{k} /$ but not the phonological ones, stem allomorphy occurs. Merchant (2015) is concerned with similar stem allomorphy in Modern Greek, and a similar proposal is applicable here. Recall that roots ending in labials and velars instead tend to show consonant mutation (and some also show rootinternal vowel changes), as seen in (21) (repeated from 12):

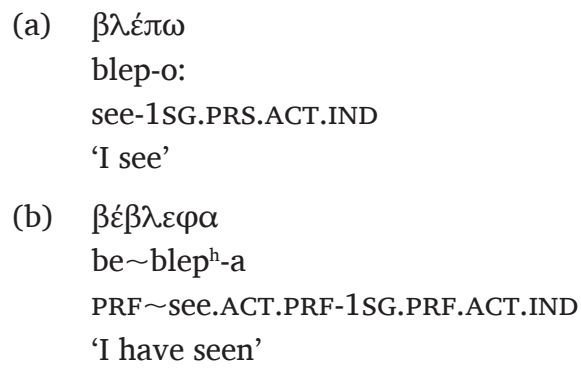

These changes appear in exactly the same morphosyntactic environments that $-/ \mathrm{k} /$ does (active voice, perfect aspect, not in future infinitives or future participles). Rather than instantiating the Voice head, though, these are roots; their insertion thus depends on a span that includes Voice[active] (〈Voice, Aspect, Tense $\rangle$ ). Below are the relevant rules for a sampling of roots: ${ }^{26}$

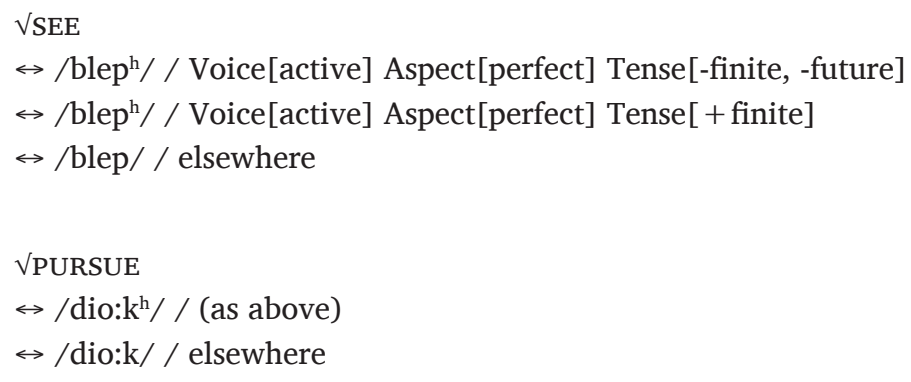

$$
\begin{aligned}
& \text { VPURSUE } \\
& \leftrightarrow \text { /dio: } \mathrm{k}^{\mathrm{h}} / \text { / (as above) } \\
& \leftrightarrow / \text { dio:k/ / elsewhere }
\end{aligned}
$$

Some roots ending in liquids and nasals add an /e:/ to the stem as well as taking the $-/ \mathrm{k} / \mathrm{suffix}$.

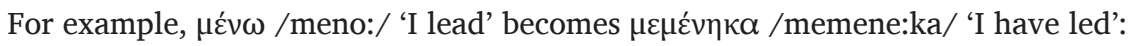

$$
\begin{aligned}
\sqrt{ } \text { LEAD } & \leftrightarrow / \text { mene:/ / (as above) } \\
& \leftrightarrow / \text { men/ / elsewhere }
\end{aligned}
$$

This does not present a problem for our rule in (19), as $-/ \mathrm{k} /$ is inserted after vowels - stems with allomorphs ending in /e:/ will still suffix $-/ \mathrm{k} /$, as expected. Roots ending in dentals drop the dental before suffixing $-/ \mathrm{k} /$; they will also both have a stem allomorph and be subject to the rule in (19). Still other, more irregular, stems show other types of changes; for example, $\lambda \varepsilon i ́ \tau \omega$ /leipo:/ 'I leave' becomes $\lambda \varepsilon ́ \lambda$ oเ $\alpha$ /leloipa/ 'I have left', undergoing stem-internal vowel changes without a stem-final labial consonant change.

$$
\begin{aligned}
\text { VLEAVE } & \leftrightarrow \text { /loip/ / (as above) } \\
& \leftrightarrow \text { /leip/ / elsewhere }
\end{aligned}
$$

In (26) I give the structure (with Vocabulary Items) for /eleloip.../ '...had left', parallel to the structure for the $-/ \mathrm{k} /$ suffixing verb given in (16):

26 While many verbs show irregularities in this form, there are recognizable regularities in the stems ending in labials and velars, as noted in Table 4: A number of labial-ending stems change that labial to a [ $\mathrm{p}^{\mathrm{h}}$ ], and a number of velar-ending stems change that labial to a $\left[\mathrm{k}^{\mathrm{h}}\right]$. Though I do not address it in detail here, these phonological regularities that apply to only small portion of the lexicon could be captured with Readjustment Rules (e.g., $\checkmark$ [-syllabic, + labial] \# $\rightarrow\left[\mathrm{p}^{\mathrm{h}}\right] /$ vblep, $\vee \ldots \ldots$ [perfect $] ; \vee$ [-syllabic, + velar] $\# \rightarrow\left[\mathrm{k}^{\mathrm{h}}\right] /$ Vdio:k, $\vee \ldots \ldots$... [perfect] $)$, which are Distributed Morphology's typical way of addressing such sub-regularities; or, from a more strictly phonological approach, with cophonologies, indexed constraints (see Inkelas \& Zoll 2007 for a comparison of the two approaches), or floating features for, e.g., Tense and Aspect (for some related work on Modern Greek, see e.g. Markopoulos 2018). 


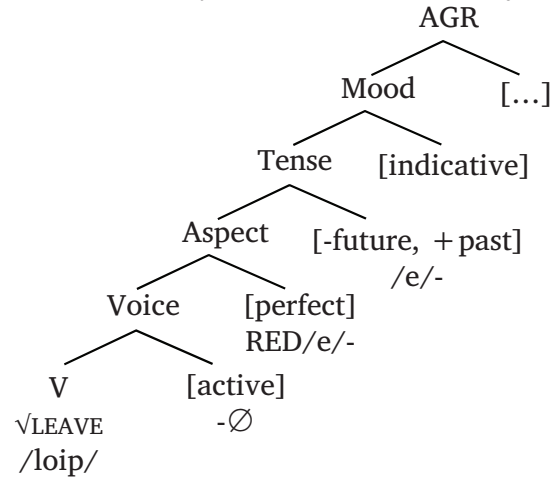

A span-based analysis allows us to easily account for the active voice perfect data in Greek. In the next section I briefly explore several alternative approaches and show why these accounts are dispreferable to the above analysis.

\subsection{Alternative analyses}

Clearly, suffixation of $-/ \mathrm{k}$ / or the analogous stem allomorphy is conditioned by perfect aspect in some way. One possibility would be that $-/ \mathrm{k} /$ somehow also instantiates Aspect along with RED/e/-, and only in the presence of a (hierarchically lower) active Voice head. Since there are two phonological pieces, presumably these would represent two distinct Vocabulary Items, both with the same context for insertion into the Aspect node (namely, [perfect]) - a situation that is not remediable using the usual tools of Distributed Morphology. The Subset Principle cannot decide between these Vocabulary Items, and we wouldn't want it to, as both appear in the output. Although the Vocabulary Item for $-/ \mathrm{k} /$ would require the presence of active voice in its context somehow, it cannot simply be an active voice allomorph of the perfect, as RED/e/appears in the active voice as well. Even given a solution to the first problem, we would end up with two Vocabulary Items that appear on either side of the verb root.

Schreiner \& Schildmier Stone (2016) face a seemingly similar problem in the mood marking of Cherokee. They argue that the so-called "future" markers ta- and - $i$ together constitute a single, two-part affix (essentially a circumfix), instantiating the head of a ModalP specified for the feature [Circumstantial]. The analysis they adopt involves Müller's (2007) rule of Enrichment, intended as a counterpart of Impoverishment (Halle 1997). Müller proposes Enrichment as a morphological process that doubles an existing feature after syntactic operations are complete but before Vocabulary Insertion begins. Schreiner \& Schildmier Stone propose that in Cherokee, a language-specific rule of Enrichment operates on a Modal head specified for [Circumstantial], doubling the feature. This yields a situation in which there are two [Circumstantial] features when Vocabulary Insertion begins. This triggers Fission (Noyer 1992/1997) of the Modal position of exponence, yielding two nodes specified for the same feature. Both Vocabulary Items specified for [Circumstantial] can then be inserted.

A similar approach could be taken with Classical Greek, with Enrichment doubling the feature [perfect] and Fission dividing the Aspect node. The next question is how the two Vocabulary Items end up on either side of the verb root (Schreiner \& Schildmier Stone do not make a detailed proposal). Assuming linearization happens late (as in Embick \& Noyer's 2001 proposal), and the Vocabulary Items are lexically specified as prefixes or suffixes (Noyer 1992/1997), linearization would be responsible for establishing the linear order between Aspect and the root (say, after the root, given that aorist aspect marking follows the root, but this is not important). While the order of Vocabulary Insertion of the two affixes is presumably random, linearization could perhaps also establish the ordering of the two halves of Aspect with respect to each other, based on their respective affixal statuses. However, to arrive at the surface order, another operation would have to be in play to relocate the reduplicative prefix to a position before the root, for instance, Embick \& Noyer's (2001) Local Dislocation.

While this solution is arguably workable, it presents a number of disadvantages when compared to the Voice-based analysis pursued in the previous section. ${ }^{27}$ It requires a dedicated (and 
perhaps overly powerful) mechanism, Enrichment, which is not otherwise widely justified; application of Fission in a non-canonical environment; and a further mechanism to get the affixes in the correct linear order.

Another way of addressing the bipartite nature of the perfect forms would be to attribute both the stem allomorphy and affixation of $-/ \mathrm{k} /$ to stem listing, in the spirit of e.g. BermúdezOtero (2013) and Haugen (2016). ${ }^{28}$ Under this type of analysis, the [perfect] feature would be instantiated directly only once (by RED/e/-), as I have proposed, but the changes on the right side would not involve a separate Vocabulary Item. Instead, roots would undergo what amounts to contextual allomorphy in the context of the features [perfect], [active], etc. This type of analysis does not require a dedicated mechanism like Enrichment, and eliminates the need to undertake Fission in an unexpected environment, as we would be required to do under the Enrichment analysis. Local Dislocation is also avoided with a stem-listing approach, since there is no second "half" of the Fissioned Aspect head to be relocated: There is only one Vocabulary Item involved outside the root.

Despite these advantages, a completely ${ }^{29}$ stem-listing approach falls short when compared to the analysis I argued for above. In this type of approach, the $-/ \mathrm{k} /$ suffix as well as the stem allomorphy would be the result of stem listing, relegating the frequent appearance of $-/ \mathrm{k} /$ in perfects to the status of accidental homophony. This obscures the fact that $-/ \mathrm{k} /$ appears across so many forms, and that its appearance vs. the presence of stem allomorphy is phonologically predictable. The Voice-based analysis allows us to account for these regularities while avoiding the pitfalls of the Enrichment-based approach.

Finally, Christopoulos \& Petrosino (2017) suggest an analysis for Modern Greek root allomorphy that employs rebracketing (Radkevich 2010, similar in function to Fusion) to join two contiguous nodes - here, Voice and Aspect - to allow for realization by a single Vocabulary Item. In the Classical Greek perfect, however, we do not see fusion between Voice and Aspect; in the passive, for instance, we see forms like /le-lu-met ${ }^{\text {ha }}$ / - perfect reduplication, root, and then fusion of Voice, Mood, and AGR. In the active, fusion is frequently present between Mood and AGR. Neither of these facts affects the conditioning of the Vocabulary Items for Aspect (or Voice) that I call for here. Given that we are dealing with many forms that show separate exponents for Tense, Aspect, Mood, and Voice (by assumption that $-/ \mathrm{k} /$ is Voice), I do not pursue an overall Fusion (or rebracketing) approach here. An analysis of the middle or passive voice systems would require more Fusion in some forms; for instance, the aorist aspect does not appear with a separate exponent outside the active voice. I leave this pursuit for future work.

\subsection{Implications for linearization}

Finally, the Greek perfect provides an interesting testing ground for determining the order of operations for Vocabulary Insertion and linearization. Recall the Vocabulary Items competing for insertion into Voice[active] from (19), repeated here as (27):

$$
\begin{aligned}
& \text { Vocabulary Items competing for insertion into Voice[active]: } \\
& \leftrightarrow \quad /-\mathrm{k} / /[\text {-labial, -velar] _ } \text { Aspect[perfect] Tense[-finite, -future] } \\
& \leftrightarrow \quad /-\mathrm{k} / /[\text {-labial, -velar] _ Aspect[perfect] Tense[ + finite] } \\
& \leftrightarrow \quad \varnothing \text { elsewhere }
\end{aligned}
$$

The contexts for insertion of $-/ \mathrm{k} /$ over $-\varnothing$ involve both the phonology of (the right side of) the root and the (hierarchically) adjacent morphosyntax. The need for Vocabulary Insertion to be able to "read" the surface-adjacent phonology might lead us to assume a pre-Vocabulary Insertion linearization process. Embick (2010), for example, argues from data with rootconditioned allomorphy that linearization must occur before Vocabulary Insertion, and Arregi \& Nevins (2012) and Haugen \& Siddiqi (2016) assume that Vocabulary Insertion operates on a linearized syntactic representation.

28 Thanks to an anonymous reviewer for this suggestion.

29 As an anonymous reviewer rightly points out, the analysis I pursue could be seen as containing elements of stem listing - the instances of conditioned allomorphy resulting in the Vocabulary Items in (22) and (23), for example, could be analyzed equally well as listed stems. The analysis I reject is one in which all stems are listed. 
This would not be a problem for our data if the conditioning span 〈Aspect, Tense > were linearly adjacent to the Voice head. However, Aspect surfaces as a prefix (RED/e/-) and thus would not be linearly adjacent to Voice when Vocabulary Insertion began. Tense[past], too, surfaces as a prefix (/e/-). An approach under which the winning Vocabulary Items are determined based on surface (post-linearization) order of the morphemes would fail here. The choice of Vocabulary Item inserted in Voice[active] thus needs to depend instead on a hierarchically adjacent span. As Merchant (2015: 279-280) notes, linearization (by design) removes the information about the hierarchical structure built by the syntax. Given the data at hand, if linearization were to occur entirely before Vocabulary Insertion, the hierarchical information needed to determine the winning Vocabulary Items for Voice would be unavailable.

In order to allow for conditioning by both surface-adjacent phonology and hierarchicallyadjacent morphosyntactic elements, Vocabulary Insertion must proceed cyclically, and linearization must occur after Vocabulary Insertion is complete. After the hierarchical arrangement of the heads is determined by the syntax, Vocabulary Insertion will proceed from the root outwards. The choice of Vocabulary Item for the root will in some cases, as with the roots discussed in this section, be sensitive to the span of heads 〈Voice, Aspect, Tense $\rangle$. Once the root Vocabulary Item is spelled out, Vocabulary Insertion can proceed for Voice. Since linearization has not yet removed the hierarchical information, Aspect and the rest of the heads in the span are available to condition the allomorphy in the presence of the feature [active]. When Vocabulary Insertion operates on Voice[active], it can take into account the phonology of the spelled-out Vocabulary Item inserted into the root ("inward sensitivity" to phonological features, as discussed by Embick 2012), as well as the morphosyntax of the hierarchically adjacent heads.

In this section I have been discussing the conditioning of $-/ \mathrm{k} /$ and stem allomorphy that appears in certain perfect active environments. Both the suffix and stem allomorphy are conditioned by the presence of spans of hierarchically, rather than linearly, adjacent heads. The data thus provide empirical evidence for the existence of outwardly-sensitive span-conditioned allomorphy. The presence of $-/ \mathrm{k} /$ also depends on the phonology of the right side of the root. These facts taken together indicate the need for cyclic Vocabulary Insertion and a postVocabulary Insertion process of linearization. In the next section I turn to the final location of perfect-specific marking in Classical Greek, the agreement suffixes.

\section{Agreement marking and perfect aspect}

We have now seen two places in which the Greek verb reflects perfect aspect - the reduplicative prefix RED/e/-, which I have argued instantiates Aspect[perfect] itself, and the suffix -/k/ and stem allomorphy, which I have argued are the instantiation of the active Voice head and the stem being conditioned by a span of hierarchically adjacent heads including Aspect[perfect]. In this section I discuss the third reflex of perfect aspect: perfect-specific agreement suffixes. As was the case with the head Voice[active], here again the realization of a set of features depends on the presence of features across several adjacent heads: Agreement suffixes are conditioned by the combination of Aspect, Tense, Voice, and Mood. In this case, however, the conditioning span is hierarchically inside the head in question, lending empirical support for inwardlysensitive span-conditioned allomorphy. Again, the winning Vocabulary Items are determined by the presence of hierarchically but not necessarily linearly adjacent spans, pointing to a postVocabulary Insertion linearization process.

\subsection{Conditioning the agreement suffixes}

Person/number agreement suffixes in Greek resemble each other in large part across tenses and aspects for a given voice and mood. The general pattern for active and passive suffixes in the indicative mood (abstracting over tenses and aspects) is given in Table 5.

Table 6 shows the full agreement suffixes (including "theme vowels") for the present (carrying imperfective semantics), present perfect, past perfect, and future perfect active indicative.

In (28-31) I give some representative examples from the $2^{\text {nd }}$ person singular paradigms of /lu:o:/ and /blepo:/ (with /histe:mi/ for future perfect, as most verbs form their future perfect forms periphrastically): 


\begin{tabular}{lll}
\hline & Active & \multicolumn{1}{l}{ Passive } \\
\hline $1 s$ & $-V$ & - mai \\
\hline $2 s$ & $-s$ & $-V$ \\
\hline $3 s$ & $-V(n)$ & - tai $^{-}$ \\
\hline $1 p$ & - men & - met $^{\text {ha }}$ \\
\hline $2 p$ & - te & - st $^{\text {he }}$ \\
\hline $3 p$ & (Various) & - ntai \\
\hline
\end{tabular}

\begin{tabular}{lllll}
\hline & PRS IPFV & PRS PRF & PST PRF & FUT PRF \\
\hline $1 s$ & -o: & -a & -e: & -o: \\
\hline $2 s$ & -eis & -as & -e:s & -eis \\
\hline $3 s$ & -ei & -e(n) & -ei(n) & -ei \\
\hline $2 d$ & -eton & -aton & -eton & -eton \\
\hline $3 d$ & -eton & -aton & -ete:n & -eton \\
\hline $1 p$ & -omen & -amen & -emen & -omen \\
\hline $2 p$ & -ete & -ate & -ete & -ete \\
\hline $3 p$ & -ousi(n) & -asi(n) & -esan & -ousi(n) \\
\hline
\end{tabular}

Table 5 General pattern for active and passive suffixes in the indicative.

Table 6 Some agreement suffixes for the active indicative (Groton 2000).

(28)

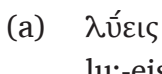

lu:-eis

release-2SG.PRS.ACT.IND

'You release'

(b) $\quad \beta \lambda \varepsilon ́ \tau \varepsilon เ \varsigma$

blep-eis

see-2SG.PRS.ACT.IND

'You see'

(29)
(a) $\lambda \varepsilon \dot{\lambda} \lambda \cup \kappa \alpha \varsigma$
le $\sim$ lu-k-as
PRF $\sim$ release-ACT.PRF-2SG.PRF.ACT.IND
'You have released'

(b) $\beta \varepsilon \dot{\beta} \lambda \varepsilon \varphi \alpha \varsigma$

be $\sim$ blep $^{\mathrm{h}}$-as

PRF See.ACT.PRF-2SG.PRF.ACT.IND

'You have seen'

(30)
(a) $\varepsilon \dot{\lambda} \varepsilon \lambda u ́ k \eta \varsigma$
e-le $\sim$ lu-k-e:s

PST-PRF release-ACT.PRF-2SG.PSTPRF.ACT.IND

'You had released'

(b) $\dot{\varepsilon} \beta \varepsilon \beta \lambda \dot{\varepsilon} \varphi \eta \varsigma$

e-be $\sim$ blep ${ }^{\mathrm{h}}$-e:s

PST-PRF See.ACT.PRF-2SG.PRF.ACT.IND

'You had seen'

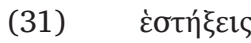

he $\sim$ ste:-k-s-eis

PRF stand.ACT.PRF-ACT.PRF-FUT-2SG.FUT.ACT.IND

'You will have stood' 
Note that the suffixes in the present and past perfects have their own distinctive vowel pattern. ${ }^{30}$ This might be unremarkable if the conditioning head were adjacent to AGR; however, Tense intervenes between Aspect[perfect] and AGR. An explanation is required for this conditioning across an intervening node. Pruning could possibly be at work in the conditioning of the Vocabulary Items in AGR in the present. Embick (2010: 54) proposes for a similar situation in Latin that Tense, when realized by $-\varnothing$, can be pruned - essentially, removed from the tree for the purposes of computing adjacency and Vocabulary Insertion. The pruning of Tense makes Aspect and Agreement linearly adjacent (Embick uses the term concatenation, - ), allowing for Vocabulary Items marking agreement to refer to the content of Aspect in their contexts for insertion. Note that the agreement affixes for the future perfect (for the two verbs that form it synthetically) are identical to the present (simple) indicative forms - that is, there is no effect of perfect aspect on agreement in the future. This is consistent with a pruning approach: If Tense has a non- $\varnothing$ exponent, as it does in the future, and therefore is not pruned, the aspectual feature cannot condition the appearance of the agreement suffixes.

That said, observe that the past perfect forms, like the future perfect forms, have an overt tense affix, and yet are conditioned by the presence of perfect aspect. Furthermore, Tense is not the only thing that affects the realization of the agreement suffixes in addition to Aspect: They also vary according to voice and mood. Table 7 gives a sampling of forms.

\begin{tabular}{|c|c|c|c|c|c|c|}
\hline & $\begin{array}{l}\text { PRS IPFV } \\
\text { ACT IND }\end{array}$ & $\begin{array}{l}\text { PRS PRF } \\
\text { ACT IND }\end{array}$ & $\begin{array}{l}\text { PRF ACT } \\
\text { SUBJ }\end{array}$ & $\begin{array}{l}\text { PRF ACT } \\
\text { OPT }\end{array}$ & $\begin{array}{l}\text { PRS PRF } \\
\text { MP IND }\end{array}$ & $\begin{array}{l}\text { FUT PRF } \\
\text { MP IND }\end{array}$ \\
\hline $1 \mathrm{~s}$ & $-0:$ & $-a$ & $-0:$ & -oimi & -mai & -omai \\
\hline $2 s$ & -eis & -as & -e:is & -ois & -sai & -e:i \\
\hline $3 s$ & -ei & $-e(n)$ & -e:i & $-o i$ & -tai & -etai \\
\hline $2 d$ & -eton & -aton & -e:ton & -oiton & $-s t^{\mathrm{h}}$ on & -est'on \\
\hline $3 d$ & -eton & -aton & -e:ton & -oite:n & $-s t^{\mathrm{h}}$ on & -esthon \\
\hline $1 p$ & -omen & -amen & -o:men & -oimen & -metha & -ometha \\
\hline $2 p$ & -ete & -ate & -e:te & -oite & $-s t^{h} e$ & -esthe \\
\hline $3 p$ & -ousi(n) & -asi(n) & -o:usi(n) & -oien & -ntai & -ontai \\
\hline
\end{tabular}

As was the case for the Voice[active] allomorphs, the realization of AGR depends again on the combination of the features across several heads - namely, Voice, Aspect, Tense, and Mood. Our Vocabulary Insertion rules must have spans that are similar to those we saw for $-/ \mathrm{k} /$. Some examples are given below: ${ }^{31}$

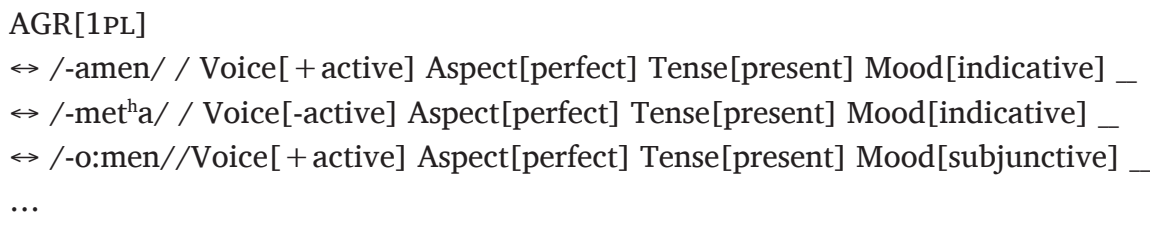

30 In some forms, particularly those in the optative mood, the instantiations of Mood and AGR are separate; in other forms, they are fused. In those forms in which two distinct pieces are not recognizable, I assume Fusion (or perhaps rebracketing, Radkevich 2010) takes place after the syntax and before Vocabulary Insertion to create one node out of two hierarchically adjacent ones. The feature(s) present in Mood are still available to condition the insertion of the correct Vocabulary Item into Aspect, and so forth.

31 Note that in moods outside the indicative, tense is generally not distinguished (e.g., there is no past or future subjunctive). In these cases, we may assume that the existing form is present tense (which always has a null instantiation) and that the other tenses are somehow semantically incompatible with the mood in question. However, there are some instances of futures outside the indicative - for instance, the future active optative - but there are no instances of pasts in these moods. This may be taken as further evidence for Grestenberger's (2015a) proposal that future -/s/ actually instantiates a higher Modal head, above Tense (and below Mood). If this were the case, these forms would be specified for present tense like their non-future counterparts; the forward-looking meaning would be contributed by the future modal.
Table 7 Some agreement suffixes for perfects (Groton 2000). 
In the case of $-/ \mathrm{k}$ / we saw outwardly-sensitive span-conditioned allomorphy; here we have inwardly-sensitive span-conditioned allomorphy. Note that, although I leave aside the details here, some of the realizations of these agreement suffixes are affected by the phonological content of the conditioning span, as is expected for inward (but not outward) sensitivity. For instance, in the perfect middle/passive indicative, second person plural $-/ \mathrm{st}^{\mathrm{h}} \mathrm{e} /$ is realized as $-/ \mathrm{t}^{\mathrm{h}} /$ when following a labial in the stem. For a past perfect active indicative, we have the following structure:

\section{Structure with features and Vocabulary Items for a past perfect $1^{\text {st }}$ person plural}

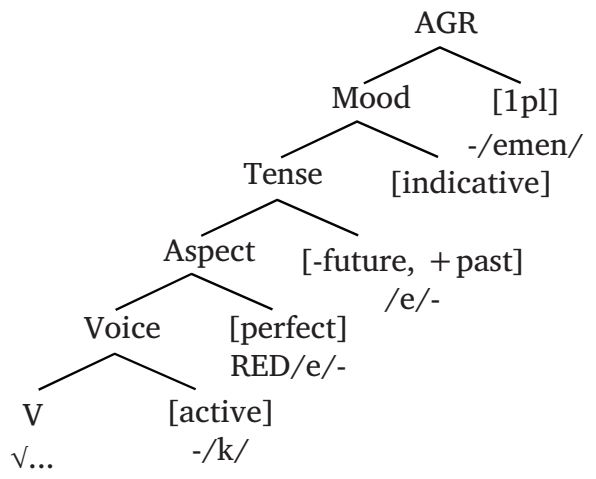

\subsection{Implications of AGR for linearization}

As was the case for $-/ \mathrm{k} /$, the Greek agreement affixation data evidence the need for a postVocabulary Insertion linearization process. Recall that the Vocabulary Items competing for insertion into Voice are conditioned by Aspect[perfect], which is instantiated by the prefix RED/e/-; this tells us that the conditioning (during Vocabulary Insertion) must take place before linearization. In the same way, the suffixal Vocabulary Items competing for insertion into AGR are conditioned by the presence of Aspect[perfect], and in some cases Tense[past] (instantiated by the prefix /e/-). The conditioning of the instantiations of AGR by these heads again demonstrates the need for linearization to occur after Vocabulary Insertion is complete.

Now that we have all of the pieces in place, let us consider a derivation in its entirety. I will use /luo:/ 'I release' as an example. First, the feature bundles are selected and form the Numeration, and the structure is built from these bundles via a series of Merge operations (etc.), yielding (34):

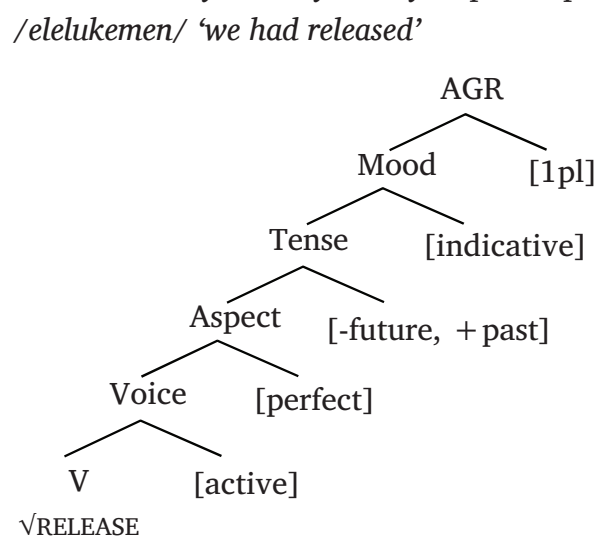

Vocabulary Insertion proceeds from the root outward, with hierarchical information conditioning the choice of several Vocabulary Items (including the form of the root in "second perfects"), resulting in (35). Vocabulary Insertion must proceed cyclically, as e.g. the choice of Vocabulary Item for Voice[active] depends on the root Vocabulary Item. 
Structure with features and Vocabulary Items for the first person plural past perfect active indicative of /luo:/ - /elelukemen/ 'we had released'

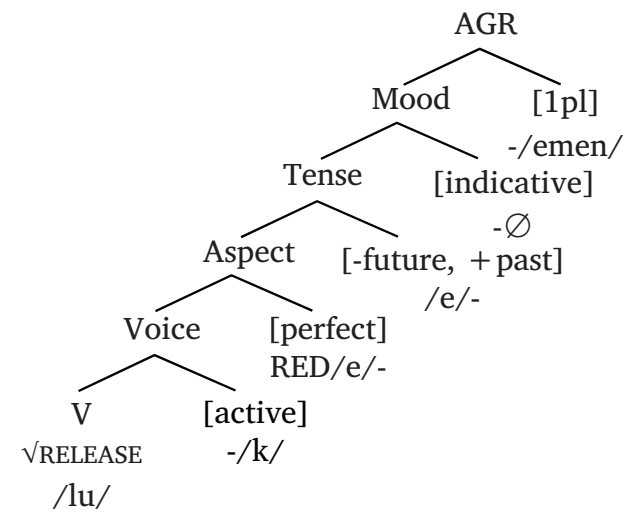

Only after Vocabulary Insertion is complete does linearization take place, yielding (36) (again employing Embick \& Noyer's 2001 notation $a * b$ to denote linear precedence and adjacency):

Output of linearization on 'we had released'

$\left[\left[e^{*}[\right.\right.$ REDe- * [[lu $\left.\left.\left.] *-k\right]\right]\right] *$-emen $]$

Finally, the linearized string, with the reduplicative morpheme linearly adjacent to the root, undergoes phonological computations. Functionally, reduplication copies the first segment of /lu/ and adds /e/, yielding /le/-. The surface string results: [elelukemen].

\section{Conclusion}

The particular effects of the feature Aspect[perfect] on the Classical Greek verb allow us to arrive at key insights into the nature of Vocabulary Insertion and linearization. I have argued here that the reduplication on the left side of perfect verb forms is the only direct exponent of the Aspect head. The $-/ \mathrm{k} /$ suffix in active forms other than future participles and future infinitives is an allomorph of Voice[active] conditioned by the span 〈Aspect, Tense〉, and the stem allomorphy that occurs in the same context is conditioned by the span $<$ Voice, Aspect, Tense $\rangle$ (both cases of outwardly sensitive span-conditioned allomorphy). The allomorphs of AGR are inwardly sensitive to the span 〈Voice, Aspect, Tense, Mood $\rangle$.

The phonological behavior of the reduplicant arises through post-syntactic and postmorphological calculations. Those calculations, modeled in Correspondence Theoretic terms by Zukoff (2017a; b), appear to operate on two separate phonological pieces, RED and the fixed segment /e/. I have contended that these pieces correlate with a single morphosyntactic unit, instantiated by a phonological piece of the shape RED/e/-, which is interpreted by the phonological component as two separate sets of "instructions" - "reduplicate (according to the output of appropriate constraint interactions)" and "pronounce /e/ (according to the output of appropriate constraint interactions)".

Finally, the data together point to a linearization process that occurs very late, after Vocabulary Insertion is complete (but still before phonological computations are undertaken). Both Voice[active] and AGR are sensitive to spans of hierarchically adjacent nodes, rather than spans of surface-contiguous heads. This is apparent due to the unique combination of prefixes and suffixes that instantiate Voice, Aspect, Mood, Tense, and AGR in Classical Greek.

The Greek perfect data thus (a) support the existence of span-conditioned allomorphy and highlight its importance for our understanding of morphosyntactic conditioning; (b) call for an extremely late phonological resolution of reduplicants; and perhaps most significantly, (c) point towards the need for a post-Vocabulary Insertion linearization process. These data must be taken into account in any claims made about Vocabulary Insertion and linearization. Data from other languages would strengthen the conclusions drawn from Greek. It remains to be seen whether the ordering called for by the Greek perfect data is universal across languages, or whether there is evidence for parameterization when it comes to the timing of linearization. ${ }^{32}$ 
The Greek data should also be borne in mind for the purposes of cross-linguistic comparisons of extended or multiple exponence (as undertaken by, e.g., Caballero \& Harris 2012; Harris 2017). While the account here will certainly not apply across the board in instances of extended exponence, the core of the analysis may be fruitfully applied in other cases.

\section{Abbreviations}

$\mathrm{ACT}=$ active voice, $\mathrm{AOR}=$ aorist aspect, $\mathrm{C}=$ consonant, $\mathrm{F}=$ feminine gender, $\mathrm{FUT}=$ future tense, $\mathrm{IND}=$ indicative mood, $\mathrm{INF}=$ infinitive, $\mathrm{IPFV}=$ imperfective aspect, $\mathrm{M}=$ masculine gender, $\mathrm{MP}=$ middle-passive voice, $\mathrm{NOM}=$ nominative case, $\mathrm{OPT}=$ optative mood, $\mathrm{PL}=$ plural number, $\mathrm{PRF}=$ perfect aspect, $\mathrm{PRS}=$ present tense, $\mathrm{PST}=$ past tense, $\mathrm{PSTPRF}=$ past perfect, $\mathrm{PTCP}=$ participle, $\mathrm{RED}=$ reduplicative Vocabulary Item, $\mathrm{SG}=$ singular number, $\mathrm{SUBJ}$ = subjunctive mood, $\mathrm{V}=$ vowel

\section{Additional file}

The additional file for this article can be found as follows:

- Appendix. Additional examples of perfect reduplication and suffixation patterns. DOI: https://doi.org/10.5334/gjgl.1400.s1

\section{Acknowledgements}

Special thanks to Joy Reeber, Jeffrey Punske, Jason Merchant, Karlos Arregi, Heidi Harley, Will Bennett, Heather Newell, Dan Siddiqi, and the audiences at the Illinois Department of Linguistics Colloquium Series, the $5^{\text {th }}$ Annual Midwest Greek Linguistics Workshop, and presentations at Georgetown University and the LSA for helpful discussion, as well as anonymous referees for their helpful comments. Earlier work on this topic was presented at the 2008 Western Conference on Linguistics and the 8th International Meeting on Greek Linguistics and published in the proceedings of those conferences (Reed 2008 and Reed 2014, respectively).

\section{Competing interests}

The author has no competing interests to declare.

\section{Author affiliation}

Sylvia L. R. Schreiner (D) orcid.org/0000-0003-2394-3477

George Mason University, US

\section{References}

Abels, Klaus \& Peter Muriungi. 2008. The focus particle in Kî̀tharaka: Syntax and semantics. Lingua 118. 687-731. DOI: https://doi.org/10.1016/j.lingua.2007.09.003

Ackerman, Farrell \& Gregory Stump. 2004. Paradigms and periphrastic expression: A study in realizationbased lexicalism. In Louisa Sadler \& Andrew Spencer (eds.), Projecting morphology, 111-157. Stanford: CSLI Publications.

Alderete, John, Jill Beckman, Laura Benua, Amalia Gnanadesikan, John McCarthy \& Suzanne Urbanczyk. 1999. Reduplication with fixed segmentism. Linguistic Inquiry 30. 327-364. DOI: https://doi. org/10.1162/002438999554101

Allen, William Sidney. 1968. Vox Graeca: The pronunciation of Classical Greek. Cambridge: Cambridge University Press.

Anderson, Stephen R. 1992. A-Morphous Morphology. Cambridge: Cambridge University Press. DOI: https://doi.org/10.1017/CBO9780511586262

Anderson, Stephen R. 2001. On some issues in morphological exponence. In Geert Booij \& Jaap van Marle (eds.), Yearbook of morphology 2000, 1-18. Dordrecht: Kluwer Academic Publishers. DOI: https://doi. org/10.1007/978-94-017-3724-1_1

Aronoff, Mark. 1976. Word Formation in Generative Grammar. Cambridge, MA: MIT Press.

Arregi, Karlos \& Andrew Nevins. 2012. Morphotactics: Basque auxiliaries and the structure of Spellout. Berlin: Springer. DOI: https://doi.org/10.1007/978-94-007-3889-8 
Baerman, Matthew \& Greville G. Corbett. 2012. Stem alternations and multiple exponence. Word Structure 5(1). 52-68. DOI: https://doi.org/10.3366/word.2012.0019

Bentein, Klaas. 2012. The periphrastic perfect in Ancient Greek: A diachronic mental space analysis. Transactions of the Philological Society 110(2). 171-211. DOI: https://doi.org/10.1111/j.1467968X.2012.01289.x

Bermúdez-Otero, Ricardo. 2013. The Spanish lexicon stores stems with theme vowels, not roots with inflectional class features. Probus 25(1). 3-103. DOI: https://doi.org/10.1515/probus-2013-0009

Bobaljik, Jonathan David. 2000. The ins and outs of contextual allomorphy. In Kleanthes K. Grohmann \& Caro Struijke (eds.), University of Maryland working papers in linguistics 10. 35-71. College Park: University of Maryland, Department of Linguistics.

Caballero, Gabriela \& Alice C. Harris. 2012. A working typology of multiple exponence. In Ferenc Kiefer, Mária Ladányi \& Péter Siptár (eds.), Current issues in morphological theory: (Ir)regularity, analogy and frequency. Selected papers from the 14th international morphology meeting, Budapest, 13-16 May 2010, 163-188. Amsterdam: John Benjamins.

Carstairs-McCarthy, Andrew. 1987. Allomorphy in inflexion. New York: Croom Helm.

Chantraine, Pierre. 1927. Histoire du parfait grec. Paris: Honoré Champion.

Christopoulos, Christos \& Roberto Petrosino. 2017. Greek root-allomorphy without spans. In Wm. G. Bennett, Lindsay Hracs, and Dennis Ryan Storoshenko (eds.), Proceedings of the 35th West Coast Conference on Formal Linguistics 2017, 151-160. Somerville, MA: Cascadilla Proceedings Project.

Cook, Toni. 2013. Morphological and phonological structure in Zulu reduplication. Philadelphia, PA: University of Pennsylvania dissertation.

Cowper, Elizabeth. 2005. The geometry of interpretable features: Infl in English and Spanish. Language 81(1). 10-46. DOI: https://doi.org/10.1353/lan.2005.0012

Deal, Amy Rose. 2016. Plural exponence in the Nez Perce DP: A DM analysis. Morphology 26(3). 313-339. DOI: https://doi. org/10.1007/s11525-015-9277-9

Embick, David. 2000. Participial structures and participial asymmetries. Ms. Massachusetts Institute of Technology.

Embick, David. 2010. Localism versus globalism in morphology and phonology (Vol. 60). Cambridge, MA: MIT Press. DOI: https://doi.org/10.7551/mitpress/9780262014229.001.0001

Embick, David. 2012. Contextual conditions on stem alternations: Illustrations from the Spanish conjugation. In Irene Franco, Sara Lusini \& Andrés L. Saab (eds.), Romance languages and linguistic theory 2010: Selected papers from "Going Romance" Leiden 2010, 21-40. Amsterdam: John Benjamins. DOI: https://doi.org/10.1075/rllt.4.02emb

Embick, David \& Rolf Noyer. 2001. Movement operations after syntax. Linguistic Inquiry 32. 555-595. DOI: https://doi.org/10.1162/002438901753373005

Felice, Lydia. 2021. A new argument for PF operations: Aspect pronouns in Gã. Talk, Linguistic Society of America 2021 Virtual Annual Meeting. DOI: https://doi.org/10.3765/plsa.v6i1.5023

Fleischhacker, Heidi Anne. 2005. Similarity in phonology: Evidence from reduplication and loan adaptation. Los Angeles, CA: UCLA dissertation.

Frampton, John. 2009. Distributed Reduplication. Cambridge, MA: MIT Press. DOI: https://doi.org/10.7551/ mitpress/9780262013260.001.0001

Gerö, Eva-Carin \& Arnim von Stechow. 2003. Tense in time: The Greek perfect. In Regine Eckardt, Klaus von Heusinger, and Christoph Schwarze (eds.), Words in time: Diachronic semantics from different points of view. Trends in Linguistics. Studies and Monographs [TLSM], 143, 251-293. Boston: de Gruyter Mouton. DOI: https://doi.org/10.1515/9783110899979

Grestenberger, Laura. 2015a. Greek reduplicated aorists and the alphathematic conjugation. Handout from the $34^{\text {th }}$ East Coast Indo-European Conference, University of Vienna. Accessed from http://www. academia.edu/download/38230006/ECIEC_34_Greek.pdf.

Grestenberger, Laura. 2015b. More span-conditioned allomorphy: Voice morphology in Classical Greek. Handout from NELS 46, Concordia University. Accessed from http://www.academia.edu/ download/39237085/NELS_handout.pdf.

Groton, Anne. 2000. From alpha to omega. Newburyport, MA: Focus Publishing.

Halle, Morris. 1997. Distributed Morphology: Impoverishment and fission. In Benjamin Bruening, Yoonjung Kang \& Martha McGinnis (eds.), MIT working papers in linguistics 30: PF: Papers at the interface, 425-450. Cambridge: MIT Working Papers in Linguistics.

Halle, Morris. 2008. Reduplication. In Robert Freidin, Carlos P. Otero, Maria Luisa Zubizarreta \& Samuel Jay Keyser (eds.), Foundational Issues in Linguistic Theory: Essays in Honor of Jean-Roger Vergnaud, 325-357. Cambridge, MA: MIT Press. DOI: https://doi.org/10.7551/ mitpress/9780262062787.003.0014

Halle, Morris \& Alec Marantz. 1993. Distributed Morphology and the Pieces of Inflection. In Ken Hale \& Samuel J. Keyser (eds.), The View from Building 20: Essays in Linguistics in Honor of Sylvain Bromberger, 111-176. Cambridge, MA: MIT Press. 
Haug, Dag. 2004. Aristotle's kinesis/energeia-test and the semantics of the Greek perfect. Linguistics 42(2). 387-418. DOI: https://doi.org/10.1515/ling.2004.013

Haugen, Jason D. 2008. Morphology at the interfaces: Reduplication and noun incorporation in Uto-Aztecan. Philadelphia: John Benjamins. DOI: https://doi.org/10.1075/la.117

Haugen, Jason D. 2009. What is the base for reduplication? Linguistic Inquiry 40(3). 505-514. DOI: https://doi.org/10.1162/ling.2009.40.3.505

Haugen, Jason D. 2010. Review of John Frampton's Distributed Reduplication. Language 86(4). 953-957. DOI: https://doi.org/10.1353/lan.2010.0029

Haugen, Jason D. 2011. Reduplication in Distributed Morphology. In Jessamyn Schertz, Alan Hogue, Dane Bell, Dan Brenner \& Samantha Wray (eds.), Coyote Papers: Working Papers in Linguistics. Volume 18: Proceedings of the Arizona Linguistics Circle 4. Tucson, AZ: University of Arizona Linguistics Circle.

Haugen, Jason D. 2016. Readjustment: rejected? In Heidi Harley \& Daniel Siddiqi (eds.), Morphological Metatheory, 303-342. Amsterdam: John Benjamins Press (Linguistic Aktuell/Linguistics Today \#229). DOI: https://doi.org/10.1075/la.229.11hau

Haugen, Jason D. \& Cathy Hicks Kennard. 2011. Base-dependence in reduplication. Morphology 21. 1-29. DOI: https://doi.org/10.1007/s11525-010-9154-5

Haugen, Jason D. \& Daniel Siddiqi. 2016. Towards a restricted realization theory: Multimorphemic monolistemicity, portmanteaux, and post-linearization spanning. Morphological Metatheory 229. 343-386. DOI: https://doi.org/10.1075/la.229.12hau

Harris, Alice C. 2017. Multiple exponence. Oxford University Press. DOI: https://doi.org/10.1093/acprof:o so/9780190464356.001.0001

Inkelas, Sharon \& Cheryl Zoll. 2007. Is grammar dependence real? A comparison between cophonological and indexed constraint approaches to morphologically conditioned phonology. Linguistics 45(1). 133-171. DOI: https://doi.org/10.1515/LING.2007.004

Liddell, Henry George \& Robert Scott. 1889. An intermediate Greek lexicon. Oxford: Oxford University Press. Impression of 2003.

Lombardi, Linda. 1997. Why Place and Voice are different: Constraint interactions and feature faithfulness in Optimality Theory. Ms., University of Maryland, College Park.

Marantz, Alec. 1982. Re reduplication. Linguistic Inquiry 13. 435-82. https://www.jstor.org/stable/4178287.

Matthews, Peter Hugoe. 1972. Inflectional morphology: A theoretical study based on aspects of Latin verb conjugation. Cambridge: Cambridge University Press.

Markopoulos, Giorgos. 2018. Phonological realization of morphosyntactic features. Thessaloniki: Aristotle University of Thessaloniki dissertation.

McCarthy, John J. 1979. Formal problems in Semitic phonology and morphology. Cambridge, MA: MIT dissertation.

McCarthy, John J. \& Alan S. Prince. 1986. Prosodic Morphology. Ms. University of Massachusetts, Amherst, and Rutgers University.

McCarthy, John J. \& Alan S. Prince. 1993. Prosodic Morphology I: Constraint interaction and satisfaction. Ms. University of Massachusetts, Amherst and Rutgers University.

McCarthy, John J. \& Alan S. Prince. 1995. Faithfulness and reduplicative identity. In Jill Beckman, Laura Walsh Dickey \& Suzanne Urbanczyk (eds.), University of Massachusetts Occasional Papers in Linguistics 18: Papers in Optimality Theory, 249-384. Amherst, MA: Graduate Linguistics Students Association.

McKay, Kenneth L. 1965. The use of the Ancient Greek perfect down to the second century A.D. Bulletin of the Institute of Classical Studies 12. 1-21. DOI: https://doi.org/10.1111/j.2041-5370.1965.tb00014.x

McKay, Kenneth L. 1980. On the Perfect and other aspects in the Greek non-literary papyri. Bulletin of the Institute of Classical Studies 27. 23-49. DOI: https://doi.org/10.1111/j.2041-5370.1980.tb00401.x

McKay, Kenneth L. 1981. On the Perfect and other aspects in New Testament Greek. Novum Testamentum 23. 289-329. DOI: https://doi.org/10.1163/156853681X00070

McKay, Kenneth L. 1992. Time and aspect in New Testament Greek. Novum Testamentum 34. 209-228. DOI: https://doi.org/10.1163/156853692X00014

Merchant, Jason. 2015. How much context is enough? Two cases of span-conditioned allomorphy. Linguistic Inquiry 46(2). 273-303. DOI: https://doi.org/10.1162/LING_a_00182

Müller, Gereon. 2007. Extended exponence by enrichment: Argument encoding in German, Archi, and Timucua. In Tatjana Scheffler, Joshua Tauberer, Aviad Eilam \& Laia Mayol (eds.), Proceedings of the 30th annual Penn linguistics colloquium, 253-266. Philadelphia: University of Pennsylvania.

Noyer, Rolf. 1992. Features, positions and affixes in autonomous morphological structure. Cambridge, MA: MIT dissertation (Published by Garland, New York, 1997).

Prince, Alan \& Paul Smolensky. 1993/2004. Optimality Theory: Constraint interaction in generative grammar. Malden, MA: Blackwell. DOI: https://doi.org/10.1002/9780470759400

Raimy, Eric. 2000. The Phonology and Morphology of Reduplication. Berlin: Mouton de Gruyter. DOI: https://doi.org/10.1515/9783110825831

Radkevich, Nina. 2010. On location: The structure of case and adpositions. Storrs, CT: University of Connecticut dissertation. 
Reed, Sylvia. 2014. A Distributed Morphology analysis of tense and aspect in Greek. In Annamaria Bartolotta (ed.), The Greek verb. Morphology, syntax, and semantics. Proceedings of the 8th International Meeting on Greek Linguistics, Agrigento, October 1-3, 2009, 277-290. Walpole, MA: Peeters, Louvainla-Neuve. http://hdl.handle.net/10447/80144.

Reed, Sylvia L. 2008. A position class analysis of the Greek verbal paradigm. In Michael Grosvald and Dionne Soares (eds.), Proceedings of the thirty-eighth Western Conference On Linguistics, 277-289. Davis, CA.

Rijksbaron, Albert. 1984. The syntax and semantics of the verb in Classical Greek. Amsterdam: J.C. Gieben.

Ringe, Donald A. 1984. The perfect tenses in Greek inscriptions. New Haven, CT: Yale University dissertation.

Schreiner, Sylvia L. R. \& Megan Schildmier Stone. 2016. A future modal in Cherokee: A special case of distributed exponence. Morphology 26(1). 33-63. DOI: https://doi.org/10.1007/s11525-015-9270-3

Shaw, Patricia A. 2005. Non-adjacency in reduplication. In Bernhard Hurch (ed.), Studies on Reduplication, 161-210. Berlin: Mouton de Gruyter. DOI: https://doi.org/10.1515/9783110911466.161

Sicking, C. M. J. \& Peter Stork. 1996. Two studies in the semantics of the verb in Classical Greek. Leiden: E.J. Brill. DOI: https://doi.org/10.1163/9789004329867

Smyth, Herbert Weir. 1920. Greek Grammar. Harvard, MA: Harvard University Press.

Steriade, Donca. 1982. Greek prosodies and the nature of syllabification. Cambridge, MA: MIT dissertation.

Steriade, Donca. 1988. Reduplication and syllable transfer in Sanskrit and elsewhere. Phonology Yearbook 5. 73-155. DOI: https://doi.org/10.1017/S0952675700002190

Svenonius, Peter. 2012. Spanning. Ms. University of Tromsø, CASTL.

Taraldsen, Knut Tarald. 2010. The nanosyntax of Nguni noun class prefixes and concords. Lingua 120. 1522-1548. DOI: https://doi.org/10.1016/j.lingua.2009.10.004

Teodorsson, Sven-Tage. 1979. On the pronunciation of Ancient Greek zeta. Lingua 47(4). 323-332. DOI: https://doi.org/10.1016/0024-3841(79)90078-0

Travis, Lisa. 1999. A syntactician's view of reduplication. In Proceedings of AFLA VI: The Sixth Meeting of the Austronesian Formal Linguistics Association. Toronto Working Papers in Linguistics 16(2). 313-331. Toronto: Toronto WPIL.

Travis, Lisa deMena. 2001. The syntax of reduplication. North East Linguistics Society 31(2). 455-469.

Urbanczyk, Suzanne. 2000. The bases of double reduplication. In Roger Billerey \& Brooke Danielle Lillehaugen (eds.), WCCFL 19: Proceedings of the 19th West Coast Conference on Formal Linguistics, 173-183. Somerville, MA: Cascadilla Press.

Wackernagel, Jakob. 1904. Studien zum griechischen Perfektum. Göttingen: Göttingen University dissertation.

Wilbur, Ronnie Bring. 1973. The phonology of reduplication. Champaign-Urbana: University of Illinois dissertation.

Williams, Edwin. 2003. Representation Theory. Cambridge, MA: MIT Press.

Zukoff, Sam. 2017a. The reduplicative system of Ancient Greek and a new analysis of Attic reduplication. Linguistic Inquiry 48(3). 459-497. DOI: https://doi.org/10.1162/ling_a_00250

Zukoff, Sam. 2017b. Indo-European Reduplication: Synchrony, diachrony, and theory. Cambridge, MA: Massachusetts Institute of Technology dissertation.

Zuraw, Kie. 2002. Aggressive reduplication. Phonology 19(3). 395-439. DOI: https://doi.org/10.1017/ S095267570300441X
TO CITE THIS ARTICLE:

Schreiner, Sylvia L. R. 2021. Span-conditioned allomorphy and late linearization: Evidence from the Classical Greek perfect. Glossa: a journal of general linguistics 6(1): 64. 1-28. DOI: https:// doi.org/10.5334/gjgl.1400

Submitted: 29 July 2020 Accepted: 22 January 2021 Published: 10 May 2021

\section{COPYRIGHT:}

(c) 2021 The Author(s). This is an open-access article distributed under the terms of the Creative Commons Attribution 4.0 International License (CC-BY 4.0), which permits unrestricted use, distribution, and reproduction in any medium, provided the original author and source are credited. See http:// creativecommons.org/ licenses/by/4.0/.

Glossa: a journal of general linguistics is a peer-reviewed open access journal published by Ubiquity Press. 